\title{
Top-down, bottom-up and physical controls on diatom-diazotroph assemblage growth in the Amazon River plume
}

\author{
M. R. Stukel, V. J. Coles, M. T. Brooks, and R. R. Hood \\ University of Maryland Center for Environmental Science, Horn Point Laboratory, Cambridge, Maryland 21613, USA \\ Correspondence to: M. R. Stukel (mstukel@umces.edu)
}

\begin{abstract}
The nutrient-rich waters of the Amazon River plume (ARP) support dense blooms of diatom-diazotroph assemblages (DDAs) that introduce large quantities of new nitrogen to the planktonic ecosystem and, unlike other nitrogen-fixers, are likely to directly fuel vertical carbon flux. To investigate the factors controlling DDA blooms, we develop a five phytoplankton (cyanobacteria, diatoms, unicellular microbial diazotrophs, DDAs, and Trichodesmium), two zooplankton model and embed it within a $1 / 6^{\circ}$ resolution physical model of the tropical and subtropical Atlantic. The model generates realistic DDA blooms in the ARP and also exhibits basin-wide primary production, nitrogen fixation, and grazing rates consistent with observed values. By following ARP water parcels with synthetic Lagrangian drifters released at the river mouth we are able to assess the relative impacts of grazing, nutrient supply, and physical forcing on DDA bloom formation. DDA bloom formation is stimulated in the nitrogen-poor and silica-rich water of the ARP by decreases in grazing pressure when mesozooplankton (which co-occur in high densities with coastal diatom blooms) concentrations decrease. Bloom termination is driven primarily by silica limitation of the DDAs. In agreement with in situ data, this net growth niche for DDAs exists in a salinity range from $\sim 20-34$ PSU, although this co-occurrence is coincidental rather than causative. Because net growth rates are relatively modest, bloom formation in ARP water parcels depends critically on the time spent in this ideal habitat, with high DDA biomass only occurring when water parcels spent $>23$ days in the optimal habitat niche.
\end{abstract}

\section{Introduction}

The Amazon River discharges $1.93 \times 10^{5} \mathrm{~m}^{3} \mathrm{~s}^{-1}$ (Perry et al., 1996) of nutrient-rich freshwater into the western tropical North Atlantic. This low-salinity water forms a surface plume of up to $1.2 \times 10^{6} \mathrm{~km}^{2}$ that can extend greater than $3000 \mathrm{~km}$ from the river mouth (Hu et al., 2004) and supports a successional series of phytoplankton communities within the gradient from rich coastal waters to oligotrophic offshore regions where the plume dissipates into the tropical and subtropical Atlantic. Subramaniam et al. (2008) defined three regions within the plume (oligohaline, mesohaline, and oceanic) each supporting distinct phytoplankton assemblages. The eutrophic oligohaline region supported a community of coastal diatom species concentrated near the surface due to the low light transmission within the plume. The coastal diatoms transitioned to diatom-diazotroph assemblages (DDAs) in the mesohaline waters, presumably due to nitrate depletion, leading to high $\mathrm{N}_{2}$-fixation (Nfix) and carbon export rates. Offshore, in the oceanic regions, the DDAs were replaced by a typical oceanic phytoplankton distribution with Trichodesmium dominating the $\mathrm{N}_{2}$-fixing assemblage and significantly reduced Nfix rates. Subramaniam et al. (2008) attribute this successional cycle to a series of bottom-up controls of the phytoplankton community.

While this bottom-up, or nutrient supply, control mechanism is plausible and consistent with in situ patterns, it does not explain the dominance of DDAs over unicellular microbial diazotrophs (UMDs) in the plume. An alternative hypothesis would state that top-down, or grazing, control of UMDs by protozoa offers DDAs a competitive advantage in the low-nitrogen mesohaline waters. Furthermore, high mesozooplankton grazing pressure may be necessary to control populations of DDAs in the coastal regions, while DDAs may be outcompeted by the relatively grazer-resistant Trichodesmium in the oceanic regions where growth rates of all diazotrophs are likely lower.

Regardless of the ecological mechanisms promoting their growth, Nfix by DDAs (rather than UMDs and Trichodesmium) in the plume may lead to vastly different fates for the nitrogen and carbon they fix. DDAs are non-obligate 
endosymbioses between diatoms from several different genera (including Hemiaulus, Rhizosolenia, and Chaetoceros) and diazotrophic cyanobacteria. The diatom hosts and the cyanobacterial symbionts can be found free-living in the ocean, and horizontal transfer between cells and vertical transmission from host to daughter cell are both common. When in association, the diazotrophs (e.g. Richelia and Calothrix) typically fix $\mathrm{N}_{2}$ from within heterocystous cells that appear to be localized in different regions of the diatom depending on the host species (Foster and O'Mullan, 2008). DDAs have been found throughout the oceans (Foster and O'Mullan, 2008), but were found at their highest concentrations in the ARP (Carpenter et al., 1999; Subramaniam et al., 2008). Nitrogen isotopes and analysis of sediment cores also suggest that they may play an increased role in global biogeochemistry during stratified oceanic periods (Kemp and Villareal, 2013).

Unlike Trichodesmium and typical UMDs (such as Crocosphaera), siliceous DDAs are significantly denser than water and hence likely to sink out of the euphotic zone, either as individual cells, aggregates, or after grazing and packaging into fecal pellets. Their presence thus may catalyze the export of carbon to deeper depths. The mesohaline region characterized by DDA blooms has been found to have higher rates of carbon export and dissolved inorganic carbon (DIC) drawdown (Cooley and Yager, 2006; Subramaniam et al., 2008). Despite this potentially important and unique biogeochemical role for DDAs, biogeochemical models that incorporate diazotrophy have primarily focused solely on Trichodesmium (Coles and Hood, 2007; Hood et al., 2004; Moore et al., 2006; Yoshikawa et al., 2013). An interesting exception to this pattern was made by Monteiro et al. (2010), who studied the competition between 78 species of randomly generated phytoplankton including three classes of diazotrophs representing Trichodesmium, DDAs, and UMDs. The authors noted, however, that their model did not appear to represent DDAs as accurately as Trichodesmium and UMD, however validation data are sparse.

To investigate both the control mechanisms of ecological succession and its biogeochemical effects in the Amazon River plume (ARP) and tropical North Atlantic we created a five-phytoplankton model (DIAZO; Diazotroph Interactions with Algae and Zooplankton in the Ocean) and embedded it within a detailed three-dimensional physical model of the tropical and subtropical Atlantic (Coles et al., 2013). We compare the model's mean rates to measurements made throughout the North Atlantic, but also focus specifically on the model's ability to replicate the DDA-salinity relationships in the ARP found by Subramaniam et al. (2008). A key feature of our work is the use of synthetic Lagrangian drifters, which allow us to track parcels of river water as they enter the Western Tropical North Atlantic and simultaneously determine DDA concentrations and growth and loss rates. We show that DDA bloom dynamics are driven by the interplay of top-down and bottom-up forcing with physically driven dilution with oligotrophic water.

\section{Methods}

\subsection{Numerical and physical framework}

The DIAZO ecological model (explained below) was implemented within a $1 / 6^{\circ}$ Hybrid Coordinate Ocean Model (HYCOM) physical framework extending from $15^{\circ} \mathrm{S}$ to $40^{\circ} \mathrm{N}$. Surface forcing from the European Centre for MediumRange Weather Forecasts reanalysis (ERA40) at 6-hourly intervals and climatological mean river inputs were used to force the model (Coles et al., 2013). The physical model was spun up for 20 years before the DIAZO model was introduced. Nutrient fields were initialized (and relaxed near the model boundaries) according to the Polar Science Center Hydrographic Climatology (Steele et al., 2001). The ecological model was implemented using a positive definite backwardEuler numerical scheme and spun up for 20 years (19791998), then run again from 1979 to 1998, with this second set of 20 years analyzed for model outputs. 25 synthetic Lagrangian surface drifters (Halliwell and Garraffo, 2002) were released in the model at random locations within a $500 \mathrm{~km}$ by $150 \mathrm{~km}$ band near the river mouth on the continental shelf every five days and tracked for a period of 400 days (or until the float ran aground).

Because growth kinetics of the mixed communities of ARP phytoplankton taxa modeled in this study have not yet been determined, we do not try to constrain our model using specifically measured in situ or laboratory values. Rather, we started with initial parameter values derived primarily from the Coles et al. (2007) Trichodesmium and PISCES (Aumont et al., 2003) models and then tuned the parameters within what we considered biologically realistic ranges until model behavior approximated the ARP ecosystem (Supplement 1).

\subsection{Ecological model construction}

Our model (DIAZO; Diazotroph Interactions with Algae and Zooplankton in the Ocean) contains three nutrients $(\mathrm{N}, \mathrm{P}$, and $\mathrm{Si}$ ), five phytoplankton (cyanobacteria $-P_{\mathrm{CYA}}$, unicellular microbial diazotrophs $-P_{\mathrm{UMD}}$, diatoms $-P_{\mathrm{DTM}}$, diatomdiazotroph assemblages $-P_{\mathrm{DDA}}$, and Trichodesmium $\left.-P_{\mathrm{Tri}}\right)$, and two zooplankton (protozoans $-Z_{\mathrm{S}}$ and mesozooplankton $-Z_{\mathrm{L}}$ ). It also contains three detrital compartments: dissolved and colloidal organic matter $\left(D_{\mathrm{C}}\right)$, small detritus $\left(D_{\mathrm{S}}\right)$, and large detritus $\left(D_{\mathrm{L}}\right)$. While all living compartments are assumed to have fixed elemental stoichiometries, detrital pools have variable stoichiometry (Fig. 1).

Our five phytoplankton communities include two pairs of diazotroph-non-diazoatroph analogs (UMDs and Cya; DDAs and Dtm). In the absence of evidence, we have taken the Occam's razor approach and assume that our analog pairs behave identically with respect to grazing, light absorption, and 
nutrient kinetics. Our diazotroph-non-diazotroph analogs thus differ only in their maximum growth rates (and of course the non-diazotroph's nitrogen requirement). Cyanobacterial growth is given below, with $\alpha$ as the phytoplankton growth efficiency (1- $\alpha$ is the fraction lost to DOC) and $m_{P}$ the phytoplankton mortality/respiration rate (for parameter values, see Supplement 1).

$\frac{\mathrm{d} P_{\text {Cya }}}{\mathrm{d} t}=\alpha \cdot U_{\text {cya }} \cdot P_{\text {Cya }}-m_{P S} \cdot P_{\text {Cya }}-G_{S, C y a} \cdot Z_{\mathrm{S}}$

$G_{\mathrm{S}, \text { Cya }}$ is the grazing rate of protozoan zooplankton $\left(Z_{S}\right)$ on cyanobacteria (explained in more detail below). $U_{\text {cya }}$ is the cyanobacterial nutrient uptake rate and is a function of light (with photoinhibition near the surface), maximum growth rate $\left(\mu_{\text {small }}\right)$, and nutrients. Nutrient limitation is modeled as a Monod-type response to limitation by either dissolved inorganic nitrogen $(\mathrm{N})$ or dissolved inorganic phosphorus (DIP).

$$
\begin{aligned}
& U_{\text {cya }}(\mathrm{N}, \mathrm{DIP}, I)=\mu_{\mathrm{small}} \cdot e^{-I / I_{\beta \mathrm{PS}}} \cdot\left(1-e^{-I / I_{P S}}\right) \\
& \cdot \min \left(\frac{N}{K_{\mathrm{S}, \mathrm{N}}+N}, \frac{\mathrm{DIP}}{K_{\mathrm{S}, \mathrm{P}}+\mathrm{DIP}}\right)
\end{aligned}
$$

UMD growth is modeled similarly to cyanobacterial growth, though we assume that nitrogen is no longer limiting, diazotrophs have a higher $\mathrm{N}: \mathrm{P}$ ratio than normal phytoplankton, and that nitrogen-fixers have a lower maximum growth rate $\left(\mu_{\text {small }} \times \vartheta_{\mathrm{S}}\right)$ due to the increased energetic cost of fixing $\mathrm{N}_{2}$, relative to utilizing $\mathrm{NO}_{3}^{-}$or $\mathrm{NH}_{4}^{+}$.

$V_{\mathrm{UMD}}(\mathrm{DIP}, I)=\mu_{\mathrm{small}} \cdot \vartheta_{\mathrm{S}} \cdot e^{-I / I_{\beta \mathrm{PS}}}$

$$
\cdot\left(1-e^{-I / I_{\mathrm{PS}}}\right) \cdot \frac{\mathrm{DIP}}{K_{\mathrm{S}, \mathrm{P}}+\mathrm{DIP}}
$$

Diatom growth is assumed to proceed with a higher maximum growth rate $\left(\mu_{\text {large }}\right)$ and a Si requirement. Diatoms have an additional loss term associated with mesozooplankton grazing (explained below).

$$
\begin{aligned}
& \frac{\mathrm{d} P_{\mathrm{DTM}}}{\mathrm{d} t}=\alpha \cdot U_{\mathrm{DTM}} \cdot P_{\mathrm{DTM}}-m_{\mathrm{PL}} \cdot P_{\mathrm{DTM}} \\
& -G_{\mathrm{S}, \mathrm{Dia}} \cdot Z_{\mathrm{S}}-G_{\mathrm{L}, \mathrm{Dia}} \cdot Z_{\mathrm{L}} \\
& U_{\mathrm{DTM}}(\mathrm{N}, \mathrm{DIP}, \mathrm{Si}, I)=\mu_{\text {large }} \cdot e^{-I / I_{\beta \mathrm{PL}}} \cdot\left(1-e^{-I / I_{\mathrm{PL}}}\right) \\
& \cdot \min \left(\frac{N}{K_{\mathrm{L}, \mathrm{N}}+N}, \frac{\mathrm{DIP}}{K_{\mathrm{L}, \mathrm{P}}+\mathrm{DIP}}, \frac{\mathrm{Si}}{K_{\mathrm{Si}}+\mathrm{Si}}\right)
\end{aligned}
$$

Since the diatom hosts in DDAs are non-obligate symbionts capable of growing in the absence of their diazotrophic partners, DDAs are assumed to behave similarly to other diatoms when DIN is relatively more abundant than $\mathrm{Si}$ or DIP, though with a slightly reduced maximum growth rate

$$
\frac{\mathrm{d} P_{\mathrm{UMD}}}{\mathrm{d} t}=\alpha \cdot V_{\mathrm{UMD}} \cdot \mathrm{P}_{\mathrm{UMD}}-m_{\mathrm{PS}} \cdot \mathrm{P}_{\mathrm{UMD}}-G_{\mathrm{S}, \mathrm{UMD}} \cdot Z_{\mathrm{S}}
$$

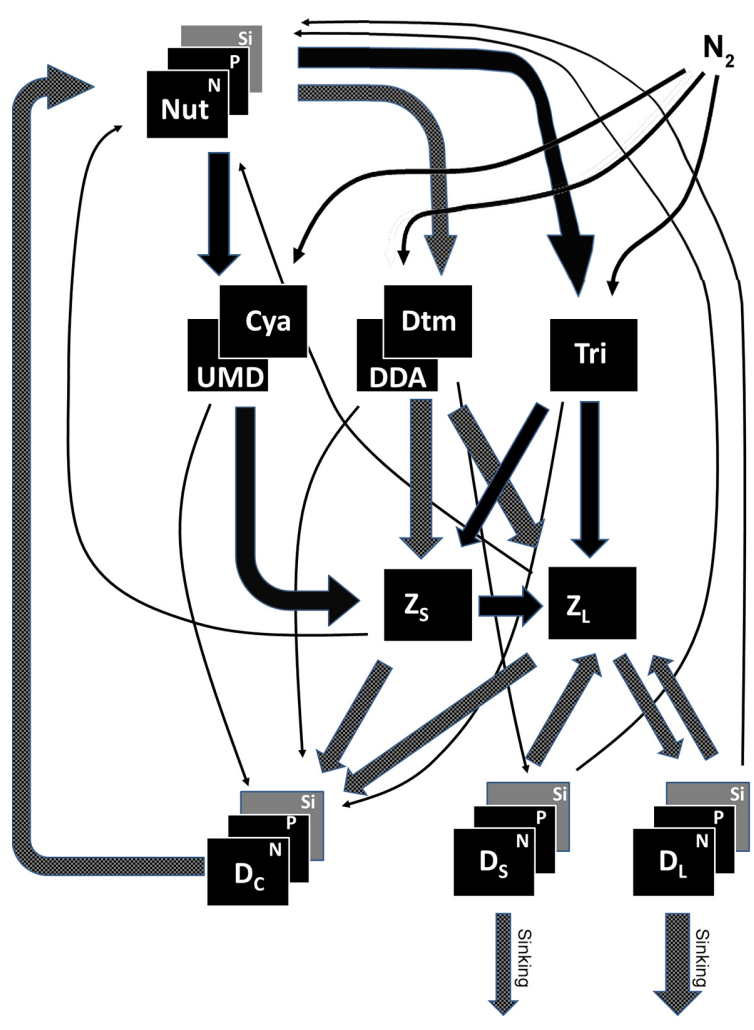

Figure 1. Model description. Model contains 19 biological compartments: Three nutrients (N, P, Si), five phytoplankton (cyanobacteria, Cya; unicellular microbial diazotrophs, UMDs; diatoms, DTM; diatom-diazotroph assemblages, DDAs; and Trichodesmium, Tri), two zooplankton (Protozoans, $Z_{\mathrm{S}}$; and mesozooplankton, $Z_{\mathrm{L}}$ ), and three detrital size classes (dissolved and colloidal detritus, $D_{\mathrm{C}}$; small detritus, $D_{\mathrm{S}}$, and large detritus, $D_{\mathrm{L}}$ ) each of which have three different element pools $(\mathrm{N}, \mathrm{P}, \mathrm{Si})$ to allow variable stoichiometry of the detritus. Arrows depict model flows (transfer functions). Thin black arrows are minor flows. Solid black arrows are flows of only $\mathrm{N}$ and $\mathrm{P}$. Hashed black arrows are flows of N, P, and Si.

$\left(\mu_{\text {large }} \times \vartheta_{\mathrm{L}}\right)$. When DIN is limiting, DDAs continue to grow, but at a much reduced maximum growth rate $\left(\mu_{\text {large }} \times \vartheta_{\text {Nif }}\right)$, such that rates of change concerning DDAs are governed by the equations:

$$
\begin{aligned}
& \frac{\mathrm{d} P_{\mathrm{DDA}}}{\mathrm{d} t}=\alpha \cdot V_{\mathrm{DDA}} \cdot P_{\mathrm{DTM}}-m_{\mathrm{PL}} \cdot P_{\mathrm{DDA}} \\
& -G_{\mathrm{S}, \mathrm{DDA}} \cdot Z_{\mathrm{S}}-G_{\mathrm{L}, \mathrm{DDA}} \cdot Z_{\mathrm{L}} \\
& V_{\mathrm{DDA}}(\mathrm{N}, \mathrm{DIP}, \mathrm{Si}, I)=\mu_{\text {large }} \cdot \vartheta_{\mathrm{L}} \cdot e^{-I / I_{\beta \mathrm{PL}}} \\
& \cdot\left(1-e^{-\frac{I}{I_{\mathrm{PL}}}}\right) \cdot \min \left(\frac{N}{K_{\mathrm{L}, \mathrm{N}}+N}, \frac{\mathrm{DIP}}{K_{\mathrm{L}, \mathrm{P}}+\mathrm{DIP}}, \frac{\mathrm{Si}}{K_{\mathrm{Si}}+\mathrm{Si}}\right) \\
& +\mu_{\operatorname{large}} \cdot \vartheta_{\mathrm{Nif}} \cdot e^{-I / I_{\beta \mathrm{PL}}} \\
& \cdot\left(1-e^{-\frac{I}{I_{\mathrm{PL}}}}\right) \cdot\left(\min \left(\frac{\mathrm{DIP}}{K_{\mathrm{L}, \mathrm{P}}+\mathrm{DIP}}, \frac{\mathrm{Si}}{K_{\mathrm{Si}}+\mathrm{Si}}\right)\right. \\
& \left.-\min \left(\frac{N}{K_{\mathrm{L}, \mathrm{N}}+N}, \frac{\mathrm{DIP}}{K_{\mathrm{L}, \mathrm{P}}+\mathrm{DIP}}, \frac{\mathrm{Si}}{K_{\mathrm{Si}}+\mathrm{Si}}\right)\right)
\end{aligned}
$$


thus when nitrogen is not limiting, $V_{\mathrm{DDA}}$ reduces to $\vartheta_{\mathrm{L}} \times$ $F$ (DIP, Si, $I$ ) and in the limit as $N$ approaches $0, V_{\mathrm{DDA}}$ reduces to $\vartheta_{\text {Nif }} \times F(\mathrm{DIP}, \mathrm{Si}, I)$, where

$$
\begin{aligned}
& F(\mathrm{DIP}, \mathrm{Si}, I)=\mu_{\text {large }} \cdot e^{-I / I_{\beta \mathrm{PL}}} \cdot\left(1-e^{-\frac{I}{I_{\mathrm{PL}}}}\right) \\
& \cdot \min \left(\frac{\mathrm{DIP}}{K_{\mathrm{L}, \mathrm{P}}+\mathrm{DIP}}, \frac{\mathrm{Si}}{K_{S i}+\mathrm{Si}}\right) .
\end{aligned}
$$

As in Hood et al. (2001), Trichodesmium is parameterized with a lower growth rate $\left(\mu_{\mathrm{Tri}}\right)$ than the other phytoplankton, but without photoinhibition. Both protozoan and metazoan zooplankton are assumed capable of ingesting Trichodesmium, though both grazers are assumed to preferentially graze smaller phytoplankton rather than Trichodesmium.

$$
\begin{aligned}
& \frac{\mathrm{d} P_{\text {Tri }}}{\mathrm{d} t}=\alpha \cdot V_{\mathrm{tri}}(\mathrm{DIP}, I) \cdot P_{\mathrm{Tri}}-m_{\mathrm{PT}} \cdot P_{\mathrm{Tri}} \\
& -G_{\mathrm{S}, \mathrm{Tri}} \cdot Z_{\mathrm{S}}-G_{\mathrm{L}, \mathrm{Tri}} \cdot Z_{\mathrm{L}} \\
& V_{\mathrm{Tri}}(\mathrm{DIP}, I)=\mu_{\mathrm{Tri}} \cdot\left(1-e^{-I / I_{\mathrm{PT}}}\right) \cdot \frac{\mathrm{DIP}}{K_{\mathrm{T}, \mathrm{P}}+\mathrm{DIP}}
\end{aligned}
$$

Protozoan zooplankton $\left(Z_{\mathrm{S}}\right)$ are assigned a growth gross efficiency of $\gamma_{\mathrm{S}}$. They are assumed to be capable of consuming each phytoplankton group with a maximum grazing rate on the total community of $G_{\mathrm{S} 0}$. We assume preferential grazing on smaller phytoplankton such that if all phytoplankton size classes were equally abundant (with respect to biomass), $G_{\mathrm{SS}}$ (Cyanobacteria) $>G_{\mathrm{SL}}$ (Diatoms) $>G_{\mathrm{ST}}$ (Trichodesmium). We also assume that grazers cannot differentiate between nitrogen-fixing and non-nitrogen-fixing phytoplankton of the same size. Phytoplankton abundances with respect to grazing preferences are assigned based on nitrogen biomasses. Protozoans are lost to grazing by mesozooplankton as well as a linear mortality term.

$$
\frac{\mathrm{d} Z_{\mathrm{S}}}{\mathrm{d} t}=\gamma_{\mathrm{S}} \cdot \mathrm{GTS} \cdot Z_{\mathrm{S}}-m_{\mathrm{ZS}} \cdot Z_{\mathrm{S}}-G_{\mathrm{L}, \mathrm{Z}} \cdot Z_{\mathrm{L}}
$$

Total Protozoan grazing is

$$
\begin{aligned}
& \mathrm{GTS}=G_{\mathrm{S}, \mathrm{Cya}}+G_{\mathrm{S}, \mathrm{UMD}} \cdot \frac{R_{0}}{R_{n}}+G_{\mathrm{S}, \mathrm{DTM}}+G_{\mathrm{S}, \mathrm{DDA}} \\
& \cdot \frac{R_{0}}{R_{n}}+G_{\mathrm{S}, \mathrm{Tri}} \cdot \frac{R_{0}}{R_{n}}+G_{\mathrm{S}, \mathrm{DS}} \cdot \frac{D_{\mathrm{S}, \mathrm{P}} \cdot R_{0}}{D_{\mathrm{S}, \mathrm{N}}}
\end{aligned}
$$

Protozoan grazing on cyanobacteria is parameterized as

$$
\begin{aligned}
& G_{\mathrm{S}, \mathrm{Cya}}=G_{\mathrm{S} 0} \\
& \left(\frac{p_{\mathrm{SS}} \cdot\left(P_{\mathrm{Cya}}\right)}{K_{\mathrm{ZS}}+p_{\mathrm{SS}} \cdot\left(P_{\mathrm{Cya}}+P_{\mathrm{UMD}}\right)+p_{\mathrm{SL}} \cdot\left(P_{\mathrm{DTM}}+P_{\mathrm{DDA}}+D_{\mathrm{S}, \mathrm{N}}\right)+p_{S Z} \cdot Z_{\mathrm{S}}+p_{\mathrm{ST}} \cdot P_{\mathrm{Tri}}+p_{\mathrm{SD}} \cdot D_{\mathrm{L}, \mathrm{N}}}\right),
\end{aligned}
$$

where $K_{\mathrm{S}}$ was the half-saturation constant for protozoans and $p_{\mathrm{SS}}, p_{\mathrm{SL}}, p_{\mathrm{SZ}}, p_{\mathrm{ST}}$ and $p_{\mathrm{SD}}$ are the protozoan grazing preferences for cyanobacteria, diatoms, other protozoans, Trichodesmium, and large detritus, respectively. We allow for preferential grazing on the most abundant food source, which models a diverse community that adjusts to the dominant available prey. We formulate switching using the Stock and Dunne (2010) modification to the zooplankton grazing scheme of Fasham et al. (1990).

$$
\begin{aligned}
& p_{\mathrm{SS}}= \\
& \left\{\left(\pi_{\mathrm{SS}} \cdot\left(P_{\mathrm{CYa}}+P_{\mathrm{UMD}}\right)\right)^{2}+\left(\pi_{S L} \cdot\left(P_{\mathrm{DTM}}+P_{\mathrm{DDA}}+D_{\mathrm{S}, \mathrm{N}}\right)\right)^{2}+\left(\pi_{\mathrm{ST}} \cdot P_{\mathrm{Tr}}\right)^{2}+\left(\pi_{\mathrm{SZ}} \cdot Z_{\mathrm{S}}\right)^{2}+\left(\pi_{\mathrm{sD}} \cdot D_{\mathrm{L}, \mathrm{N}}\right)^{1}\right\}^{1 / 2}
\end{aligned}
$$

Mesozooplankton grow with a gross growth efficiency of $\gamma_{\mathrm{L}}$, though they also have a basal metabolic rate of $B_{\mathrm{R}}$. Mesozooplankton are grazed by an unmodeled higher predator that is assumed to covary with mesozooplankton and graze on them with the same Hollings Type 2 functional response used for the other grazers in the model (Stock and Dunne, 2010). Mesozooplankton are assumed to be capable of grazing on diatoms, protozoans, Trichodesmium, and detritus ( $\left.D_{\mathrm{L}, \mathrm{P}}\right)$. As in the PISCES model (Aumont et al., 2003), we assume a lower maximum grazing rate for mesozooplankton than protozoans $\left(G_{\mathrm{L} 0}<G_{\mathrm{S} 0}\right)$, which effectively limits the growth of mesozooplankton allowing their primary prey (diatoms) to escape grazing pressure while the protozoans keep the cyanobacteria population tightly controlled.

$$
\begin{aligned}
& \frac{\mathrm{d} Z_{\mathrm{L}}}{\mathrm{d} t}=\gamma_{\mathrm{L}} \cdot \mathrm{GTL} \cdot Z_{\mathrm{L}}-B_{\mathrm{R}} \cdot L_{Z}-m_{\mathrm{ZL}} \cdot L_{\mathrm{Z}}-\frac{G_{\mathrm{H} 0} \cdot Z_{\mathrm{L}} \cdot Z_{\mathrm{L}}}{K_{\mathrm{H}}+Z_{\mathrm{L}}} \\
& \mathrm{GTL}=G_{\mathrm{L}, \mathrm{DTM}}+G_{\mathrm{L}, \mathrm{DDA}} \cdot \frac{R_{0}}{R_{n}}+G_{\mathrm{L}, \mathrm{Tri}} \cdot \frac{R_{0}}{R_{n}}+G_{\mathrm{L}, \mathrm{Z}} \\
& +G_{\mathrm{L}, \mathrm{DS}} \frac{D_{\mathrm{S}, \mathrm{P}} \cdot R_{0}}{D_{\mathrm{S}, \mathrm{N}}}+G_{\mathrm{L}, \mathrm{DL}} \frac{D_{\mathrm{L}, \mathrm{P}} \cdot R_{0}}{D_{\mathrm{L}, \mathrm{N}}} \\
& G_{\mathrm{L}, \mathrm{DTM}}=G_{\mathrm{L} 0} \quad p_{\mathrm{LL}} \cdot P_{\mathrm{DTM}} \\
& \left(\frac{K_{\mathrm{ZL}}+p_{\mathrm{LL}} \cdot\left(P_{\mathrm{DTM}}+P_{\mathrm{DDA}}+D_{\mathrm{S}, \mathrm{N}}\right)+p_{\mathrm{LT}} \cdot P_{\mathrm{Tri}}+p_{\mathrm{LZ}} \cdot Z_{\mathrm{S}}+p_{\mathrm{LD}} \cdot D_{\mathrm{L}, \mathrm{N}}}{\mathrm{C}_{\mathrm{L}}}\right)
\end{aligned}
$$

$$
\begin{aligned}
& p_{\mathrm{LL}}= \\
& \frac{\pi_{\mathrm{LL}} \cdot\left(P_{\mathrm{DTM}}+P_{\mathrm{DDA}}+\mathrm{D}_{\mathrm{S}, \mathrm{N}}\right)}{\left\{\left(\pi_{\mathrm{LL}} \cdot\left(P_{\mathrm{DTM}}+P_{\mathrm{DDA}}+D_{\mathrm{S}, \mathrm{N}}\right)\right)^{2}+\left(\pi_{\mathrm{LT}} \cdot P_{\mathrm{Tri}}\right)^{2}+\left(\pi_{\mathrm{LZ}} \cdot Z_{\mathrm{S}}\right)^{2}+\left(\pi_{\mathrm{LD}} \cdot D_{\mathrm{L}, \mathrm{N}}\right)^{2}\right\}^{1 / 2}}
\end{aligned}
$$

Large detritus is produced as the egestion of mesozooplankton ( $\varepsilon=$ egestion efficiency). It is consumed by mesozooplankton, lost to the inorganic nutrient pool by bacteriallymediated degradation, or lost as sinking flux (Supplement 2, Eq. S1). With respect to nitrogen, the increased $\mathrm{N}: \mathrm{P}$ ratio of diazotrophs leads to an additional term representing the stoichiometrically unnecessary additional nitrogen (Supplement Eq. S2). We assume that all Si ingested by mesozooplankton passes directly to the detrital pool since zooplankton do not assimilate Si (Supplement Eq. S3).

A more slowly sinking detrital pool is composed of nonliving diatom cells, that are produced through diatom mortality and lost to bacterially-mediated degradation to dissolved nutrients and sinking (Supplement Eq. S4-6). Colloidal and 
dissolved detritus $\left(D_{\mathrm{S}}\right)$ is produced by a combination of protozoan egestion, excretion and sloppy feeding by both zooplankton groups ( $\sigma$ is the proportion of excretion and sloppy feeding that goes to the small detritus pool), exudation and mortality of all phytoplankton groups, and dissolution of large detritus. It is lost through bacterially-mediated remineralization (Supplement Eq. S7). For colloidal detrital nitrogen we again have an additional component associated with the egestion and excretion of stoichiometrically unnecessary nitrogen (Eq. S8). Colloidal Si is derived from protozoan ingestion of diatoms and diatom mortality, as well as dissolution of large detritus (Eq. S9).

Nutrients (DIN and DIP) are regenerated through grazer excretion and bacterially-mediated remineralization of colloidal and dissolved detritus (Supplement Eq. S10). We assume (following Hood et al., 2001) that diazotrophs take up DIN until they would be N-limited after which they fulfill the rest of their nitrogen budget with Nfix (Supplement Eq. S11). $\mathrm{Si}$ is generated only through the remineralization of detrital Si (Supplement Eq. S15). Parameter values used in our DIAZO base run are shown in Supplement 1.

\section{Results}

\subsection{Basin-scale model-data comparison}

To remove errors introduced in point-to-point model-data comparisons by mesoscale variability, we have taken an integrative approach to model validation. In particular, we choose to compare the large-scale patterns and basin-scale rate measurements provided by individual studies to our model results. In this section we compare our model results to in situ measurements throughout the model domain, including Nfix, primary production (PP), and grazing rates. In the following section we will more directly compare our model results within the ARP to those measured by Subramaniam et al. (2008).

On north-south transects through the central North Atlantic, Fernandez et al. (2010) found that Nfix peaked at a mean of $\sim 60 \mu \mathrm{mol} \mathrm{N} \mathrm{m} \mathrm{N}^{-2} \mathrm{~d}^{-1}$ between $5^{\circ} \mathrm{S}$ and $15^{\circ} \mathrm{N}$ and averaged 25 and $11 \mu \mathrm{mol} \mathrm{N} \mathrm{m} \mathrm{N}^{-2} \mathrm{~d}^{-1}$ in the subtropical gyre for 2007 and 2008, respectively, while Moore et al. (2009) measured a relatively constant Nfix rate by unicellular diazotrophs of $16 \mu \mathrm{mol} \mathrm{N} \mathrm{m} \mathrm{N}^{-2} \mathrm{~d}^{-1}$, but a variable contribution by Trichodesmium, which peaked at $\sim 200 \mu \mathrm{mol} \mathrm{N} \mathrm{m}{ }^{-2} \mathrm{~d}^{-1}$ between 5 and $15^{\circ} \mathrm{N}$, but was less than $40 \mu \mathrm{mol} \mathrm{N} \mathrm{m}{ }^{-2} \mathrm{~d}^{-1}$ north of $20^{\circ} \mathrm{N}$. By comparison, the model predicts an annual mean value of $145 \mu \mathrm{mol} \mathrm{N} \mathrm{m}{ }^{-2} \mathrm{~d}^{-1}$ for the central Atlantic (longitudinally) from $15^{\circ} \mathrm{S}$ to $30^{\circ} \mathrm{N}$, increasing from a minimum of $0.95 \mu \mathrm{mol} \mathrm{N} \mathrm{m} \mathrm{N}^{-2} \mathrm{~d}^{-1}$ at a coastal site in the northern region of the model to a peak in the ARP of $487 \mu \mathrm{mol}$ $\mathrm{N} \mathrm{m}^{-2} \mathrm{~d}^{-1}$. In a study specifically focused on the tropical region from the equator to $15^{\circ} \mathrm{N}$, Montoya et al. (2007) found that overall Nfix rates were not significantly different between the western $\left(60-40^{\circ} \mathrm{W}, 201 \mu \mathrm{mol} \mathrm{N} \mathrm{m}{ }^{-2} \mathrm{~d}^{-1}\right)$ and eastern $\left(40-20^{\circ} \mathrm{W}, 180 \mu \mathrm{mol} \mathrm{N} \mathrm{m}{ }^{-2} \mathrm{~d}^{-1}\right)$ regions, but that the role of unicellular diazotrophs increased significantly to the east. In our model, overall Nfix decreases slightly from west to east $\left(255 \mu \mathrm{mol} \mathrm{N} \mathrm{m} \mathrm{N} \mathrm{m}^{-2} \mathrm{~d}^{-1}\right.$ for the tropics west of $40^{\circ} \mathrm{W}$ and $179 \mu \mathrm{mol} \mathrm{N} \mathrm{m}{ }^{-2} \mathrm{~d}^{-1}$ east of $40^{\circ} \mathrm{W}$ ) and UMDs reach a peak Nfix rate of $>200 \mu \mathrm{mol} \mathrm{N} \mathrm{m}{ }^{-2} \mathrm{~d}^{-1}$ within the Caribbean which was not sampled by Montoya et al. (2007), but maintain a relatively constant (and high) proportion of total Nfix throughout most of the horizontal band from $18^{\circ} \mathrm{N}$ to $25^{\circ} \mathrm{N}$. Within the greater Mauritanian upwelling system (MUS, which we will define here as extending from the coast to $26^{\circ} \mathrm{W}$ and from $12^{\circ} \mathrm{N}$ to $30^{\circ} \mathrm{N}$ ), Rijkenberg et al. (2011) measured mean surface Nfix rates of $0.3 \mathrm{nmol} \mathrm{N} \mathrm{L} \mathrm{N}^{-1} \mathrm{~d}^{-1}$ in January and February, while in November and December Turk et al. (2011) measured significantly higher rates of $26.4 \mathrm{nmol} \mathrm{N} \mathrm{L}-1 \mathrm{~d}^{-1}$ although both studies agreed that Nfix was significantly higher in the south than the north. Our model predicted an annual mean surface value of $2.8 \mathrm{nmol} \mathrm{N}$ $\mathrm{L}^{-1} \mathrm{~d}^{-1}$ in the MUS, and a weak latitudinal trend. Overall, it appears that our model may underestimate the mean spatial variability in Nfix, although this may simply reflect high seasonal variability rectified in the model mean. Figure 2 clearly illustrates how high seasonal variability in the model is smoothed in the mean. A synthesis of in situ Nfix measurements compiled by Luo et al. (2012) exhibits much greater spatial heterogeneity than our 20 year model mean. However, a comparison to the lowest and highest Nfix months during the year 1991 (February and August, respectively) shows that for the most part model variability comes close to matching the in situ variability, and matches the in situ data in finding highest Nfix rates in the ARP. Furthermore, it is interesting to note that the seasonal pattern of Nfix varies throughout the region. For instance, Gulf of Mexico Nfix values are very high in late summer, but negligible in winter, while Nfix values in the equatorial regions and off of Southern Africa are lower in Aug than Feb (Fig. 2).

In situ PP measurements typically suggest low rates of between 160 and $280 \mathrm{mg} \mathrm{C} \mathrm{m}^{-2} \mathrm{~d}^{-1}$ in the oligotrophic subtropical gyre (Marañon et al., 2007; Perez et al., 2006; Teira et al., 2005; Tilstone et al., 2009). PP increases towards the equatorial and coastal upwelling regions, with typical values of $240-320 \mathrm{mg} \mathrm{C} \mathrm{m}^{-2} \mathrm{~d}^{-1}$ in the equatorial region (Perez et al., 2005; Poulton et al., 2006) and 400-700 mg C $\mathrm{m}^{-2} \mathrm{~d}^{-1}$ in the MUS (Davenport et al., 2002; Neuer et al., 2002). In the model, primary productivity averages $225 \mathrm{mg}$ $\mathrm{C} \mathrm{m}^{-2} \mathrm{~d}^{-1}$ across the basin, varying from a mean of $168 \mathrm{mg}$ $\mathrm{C} \mathrm{m}^{-2} \mathrm{~d}^{-1}$ in the subtropical gyre to $325 \mathrm{mg} \mathrm{C} \mathrm{m}^{-2} \mathrm{~d}^{-1}$ throughout the greater MUS, but peaking at an annual average of $1265 \mathrm{~m} \mathrm{C} \mathrm{m}^{-2} \mathrm{~d}^{-1}$ near the coast in the MUS.

Across disparate regions of the global ocean, protistan grazing tends to constitute a relatively constant proportion of phytoplankton loss terms, varying from $60 \%$ of PP in coastal environments to $75 \%$ in tropical and subtropical regions (Calbet and Landry, 2004). Within the North Atlantic 

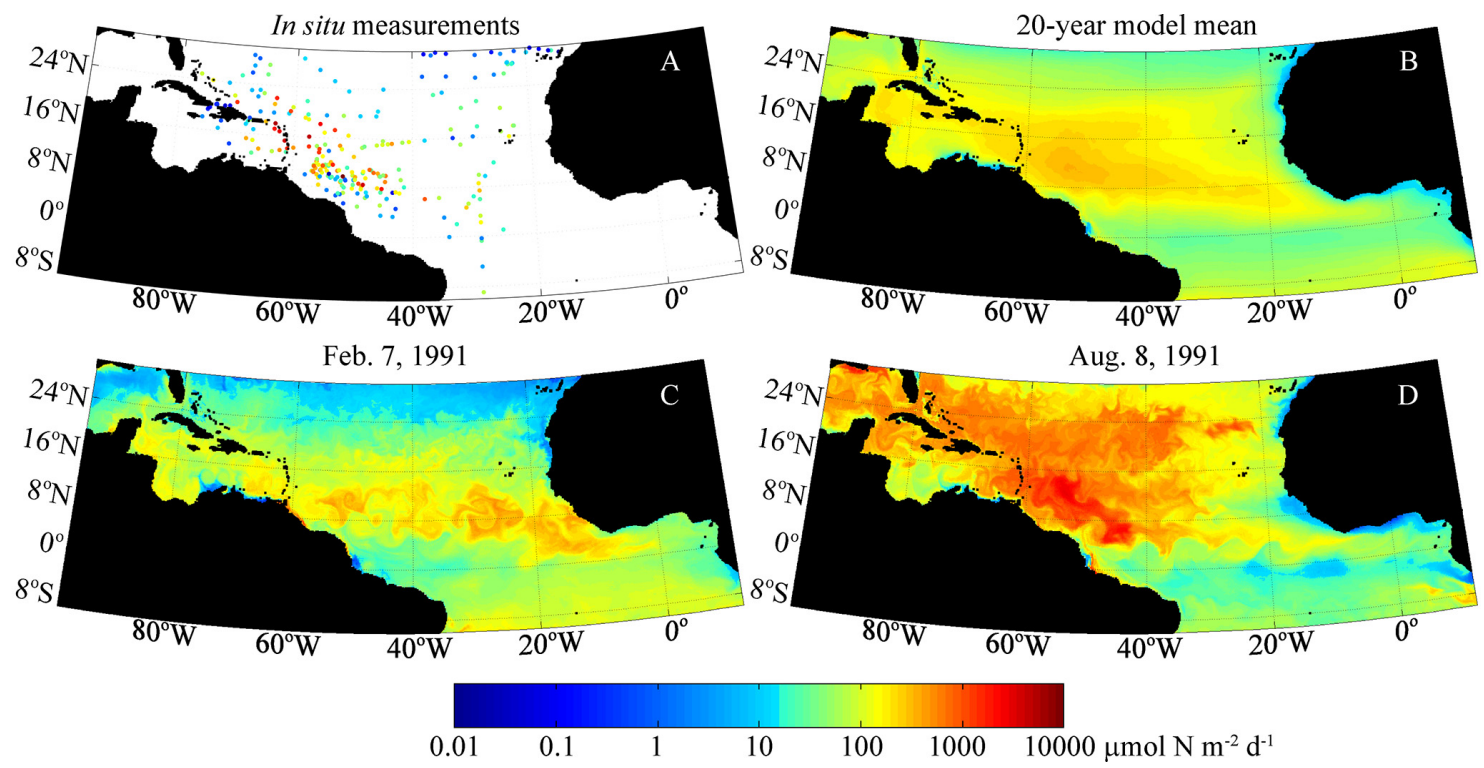

Figure 2. Basin-scale nitrogen fixation. Panel A shows in situ nitrogen fixation measurements compiled by Luo et al. (2012) on a logarithmic scale. Panels (B), (C), and (D) show model values from our DIAZO base model run representing the 20-year model mean (B), and single day values from 7 February 1991 (C) and 8 August 1991 (D). These days were chosen because they showed the lowest and highest, respectively, rates of nitrogen fixation during the "normal" year of 1991 and hence highlight the seasonal variability in the model.

subtropical gyre, Quevedo and Anadón (2001) found protistan grazing rates of $78 \% \mathrm{PP}$ at the surface and $109 \%$ at the deep chlorophyll max. Across the model domain, protistan grazing averaged $71 \%$ of particulate PP, varying from a minimum integrated annual average of $40-60 \%$ in the coastal eutrophic regions to a maximum integrated annual average of $\sim 90 \%$ in the core of the oligotrophic gyre. Globally, mesozooplankton grazing averages $\sim 12 \%$ PP (Calbet, 2001), although variability is extremely high. On a series of north-south transects through our study region, Huskin et al. (2001) measured copepod gut pigments and found that grazing ranged from an average of $4 \% \mathrm{PP}$ in the subtropical gyre to $23 \%$ PP in the tropics, while Isla et al. (2004) measured grazing rates ranging from $4-5 \%$ PP in the tropics and subtropical gyre to $16 \%$ in the MUS. Lopez and Anadón (2008) concurred with this general pattern, but found significantly higher rates of $26-112 \% \mathrm{PP}$ in the gyre and higher in upwelling regions. Conversely, Calbet et al. (2009) conducted mesozooplankton incubations and found higher relative grazing rates of $28 \% \mathrm{PP}$ in the gyre than in the MUS (6\% PP) or the tropics (17\% PP). The model showed relatively high mesozooplankton grazing rates that averaged $27 \%$ PP across the domain, varying from a minimum integrated annual average of $<10 \%$ in the core of the oligotrophic gyre to a maximum integrated annual average of $>40 \%$ in the equatorial and coastal regions.

\subsection{Amazon River plume regional model-data comparison}

The ARP is a region with high spatiotemporal variability in its physics, biogeochemistry, ecology, and sheer extent. In situ Nfix rate measurements have been concentrated in the northern summer from April to October when plume area is greatest (Hu et al., 2004) and our model predicts the highest mean ARP Nfix. Cruises in the region have measured widely differing rates of Nfix and documented different roles for the dominant diazotrophs in the ARP. Cruise tracks have typically been biased towards bloom regions, and Nfix within these blooms reaches very high rates. DDA blooms have been encountered with average Nfix rates of $3200 \mu \mathrm{mol} \mathrm{N} \mathrm{m}{ }^{-2} \mathrm{~d}^{-1}$ (Carpenter et al., 1999). Nfix by Trichodesmium in the region can also reach rates exceeding $1000 \mu \mathrm{mol} \mathrm{N} \mathrm{m} \mathrm{N}^{-2} \mathrm{~d}^{-1}$, although cruise means typically vary from $50-300 \mu \mathrm{mol} \mathrm{N} \mathrm{m}^{-2} \mathrm{~d}^{-1}$ (Capone et al., 2005; Montoya et al., 2007). UMD Nfix rates are generally lower, ranging from $20-50 \mu \mathrm{mol} \mathrm{N} \mathrm{m} \mathrm{N}^{-2} \mathrm{~d}^{-1}$ (Falcon et al., 2004; Montoya et al., 2007). Meanwhile, Subramaniam et al. (2008) measured mean Nfix rates (by acetylene reduction) throughout the region of $98 \mu \mathrm{mol} \mathrm{N} \mathrm{m}{ }^{-2} \mathrm{~d}^{-1}$ for Trichodesmium and $49 \mu \mathrm{mol} \mathrm{N} \mathrm{m}{ }^{-2} \mathrm{~d}^{-1}$ for DDAs, although they believe that the acetylene reduction vastly underestimated the Nfix of DDAs, because at mesohaline regions dominated by DDAs, ${ }^{15} \mathrm{~N}_{2}$ uptake measurements suggested vastly higher Nfix rates of $986 \mu \mathrm{mol} \mathrm{N} \mathrm{m}^{-2} \mathrm{~d}^{-1}$. For all taxa and studies, however, these high mean rates are often driven by a few extreme values. For instance, although the 

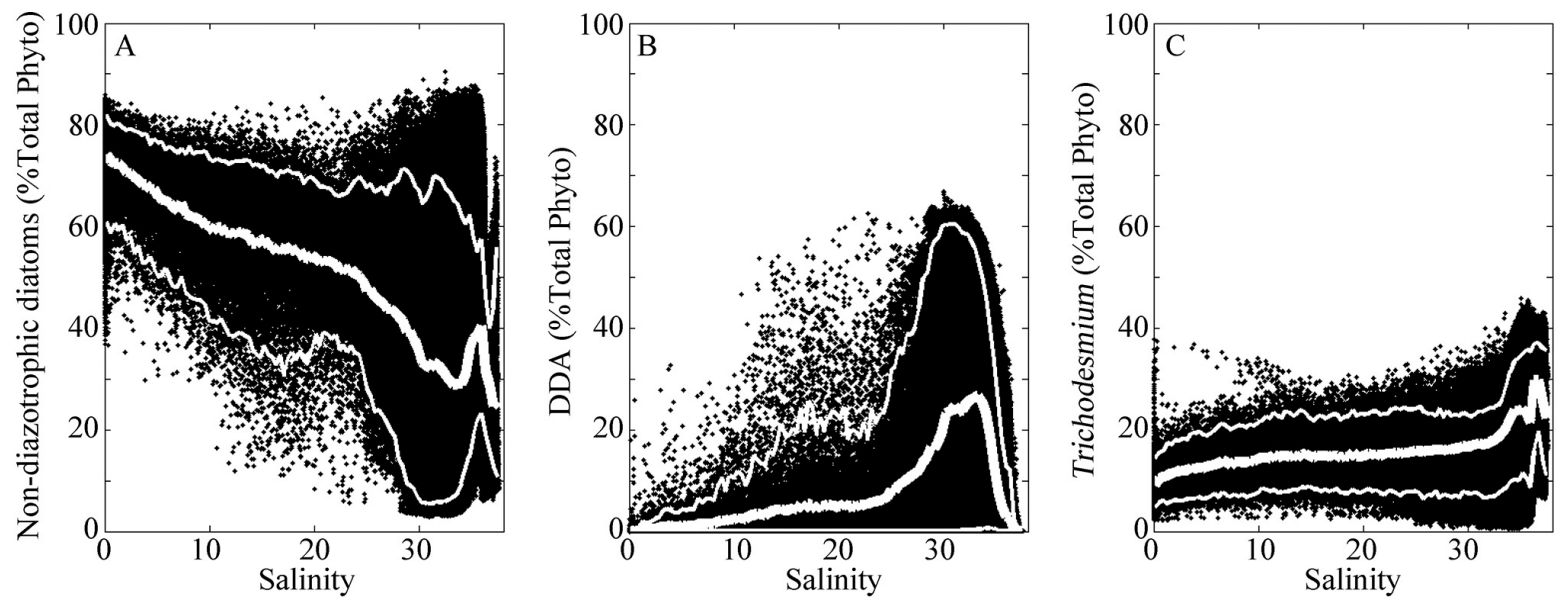

Figure 3. Percentage contribution of phytoplankton taxa to total surface phytoplankton biomass along the salinity gradient in the ARP region. Coastal diatoms (A), DDAs (B), Trichodesmium (C). Thick white lines are the model means. Thin white lines are the $95 \%$ confidence intervals.

mean Nfix at mesohaline regions measured by Subramaniam et al. (2008) was $986 \mu \mathrm{mol} \mathrm{N} \mathrm{m} \mathrm{N}^{-2} \mathrm{~d}^{-1}$, the median value was only $82 \mu \mathrm{mol} \mathrm{N} \mathrm{m} \mathrm{N}^{-2} \mathrm{~d}^{-1}$. This high patchiness is not exhibited in the model, and remains a challenge for modelers in general.

Nevertheless it is possible to draw some broad generalizations from the existing in situ measurements. Subramaniam et al. (2008) defines three distinct subregions: low-salinity (SSS $>30)$, mesohaline $(30>\mathrm{SSS}>35)$, and oceanic (SSS $>35$ ). The low salinity region is a light-limited region with a shallow euphotic zone and a phytoplankton community dominated by coastal diatoms and negligible Nfix. The mesohaline region exhibits high $\mathrm{P}: \mathrm{N}$ and $\mathrm{Si}: \mathrm{N}$ ratios, which stimulates Nfix by DDAs, although with additional contributions from Trichodesmium. The oceanic region is relatively depleted in $\mathrm{Si}$ and dominated by Trichodesmium and other cyanobacteria.

While Subramaniam et al. (2008) restricted their study to a latitudinal band from $0-15^{\circ} \mathrm{N}$, we will consider the ARP region as extending from $60-40^{\circ} \mathrm{W}$ and $0-20^{\circ} \mathrm{N}$ based on our model result that Nfix often peaked north of $15^{\circ} \mathrm{N}$, a result that actually agrees well with the results of Capone et al. (2005) and is supported by Coles et al. (2013) who found high penetration of Amazon River water into the Caribbean. Our model predicted annual mean Nfix in the ARP of $275 \mu \mathrm{mol} \mathrm{N} \mathrm{m} \mathrm{d}^{-1}$. The low-salinity region had lower Nfix rates $\left(204 \mu \mathrm{mol} \mathrm{N} \mathrm{m} \mathrm{m}^{-2} \mathrm{~d}^{-1}\right)$ and a community dominated by non-diazotrophic diatoms (49\% of total biomass, Fig. 3). In the mesohaline region mean Nfix was $372 \mu \mathrm{mol} \mathrm{N} \mathrm{m}{ }^{-2} \mathrm{~d}^{-1}$ (compared to a median of $334 \mu \mathrm{mol} \mathrm{N} \mathrm{m} \mathrm{N}^{-2} \mathrm{~d}^{-1}$ and a maximum of $3050 \mu \mathrm{mol} \mathrm{N} \mathrm{m} \mathrm{m}^{-1}$ ), suggesting that our model may have accurately captured the average conditions in the region, but perhaps missed some of the extreme blooms encountered by Subramaniam et al. (2008). Nfix was fueled by DDAs in this region (Fig. 4) which were responsible for
$299 \mu \mathrm{mol} \mathrm{N} \mathrm{m}{ }^{-2} \mathrm{~d}^{-1}$ and contributed $10 \%$ of biomass (compared to $28 \%$ estimated by Subramaniam et al., 2008). While DDA blooms were largely restricted to the mesohaline region, their concentrations within this salinity region were seasonally variable (Fig. 5). Within the high-salinity oceanic region, DDAs contributed only $3.4 \%$ of biomass (compared to $<2 \%$ estimated by Subramaniam et al., 2008) and Trichodesmium dominated Nfix, contributing $48 \%$ of the total $213 \mu \mathrm{mol} \mathrm{N} \mathrm{m} \mathrm{m}^{-2} \mathrm{~d}^{-1}$, while total biomass was dominated by the cyanobacteria (including Trichodesmium, UMDs, and Cya), which together accounted for $65 \%$ of the biomass. Mean annual patterns of diazotroph biomass in the model suggested that both Trichodesmium and DDAs peaked in the northwestern ARP, although Trichodesmium seems to monotonically decrease gradually from a maximum in the Caribbean, while DDAs peak in the region from $10-17^{\circ} \mathrm{N}$ and $60-50^{\circ} \mathrm{W}$ (Fig. 5). These general patterns agree reasonably well with the measurements of Subramaniam et al. (2008), although their cruise tracks did not extend north of $15^{\circ} \mathrm{N}$ and the large scatter in the field measurements exhibits a much larger range of variability for Trichodesmium than predicted by our annual mean values.

By defining the ARP as a system of communities optimized to varying degrees of mixing between the river and ocean water, we can use the salinity gradient to compare our model to the measurements of Subramaniam et al. (2008). Our model exhibits a linear decrease in $\mathrm{Si}$ as a function of salinity, which agrees well with the in situ data (Fig. 4b) and indicates that physical dilution with low-Si oceanic water is the primary mechanism affecting Si concentrations in the ARP. From the river to a salinity of 30 , conservative mixing accounts for $74 \%$ of Si reduction (calculated based on a two end-member mixing line with riverine and salinity $=36$ end members), compared to only a $6 \%$ DIN loss to conservative mixing. DIN : DIP ratios in the model showed 

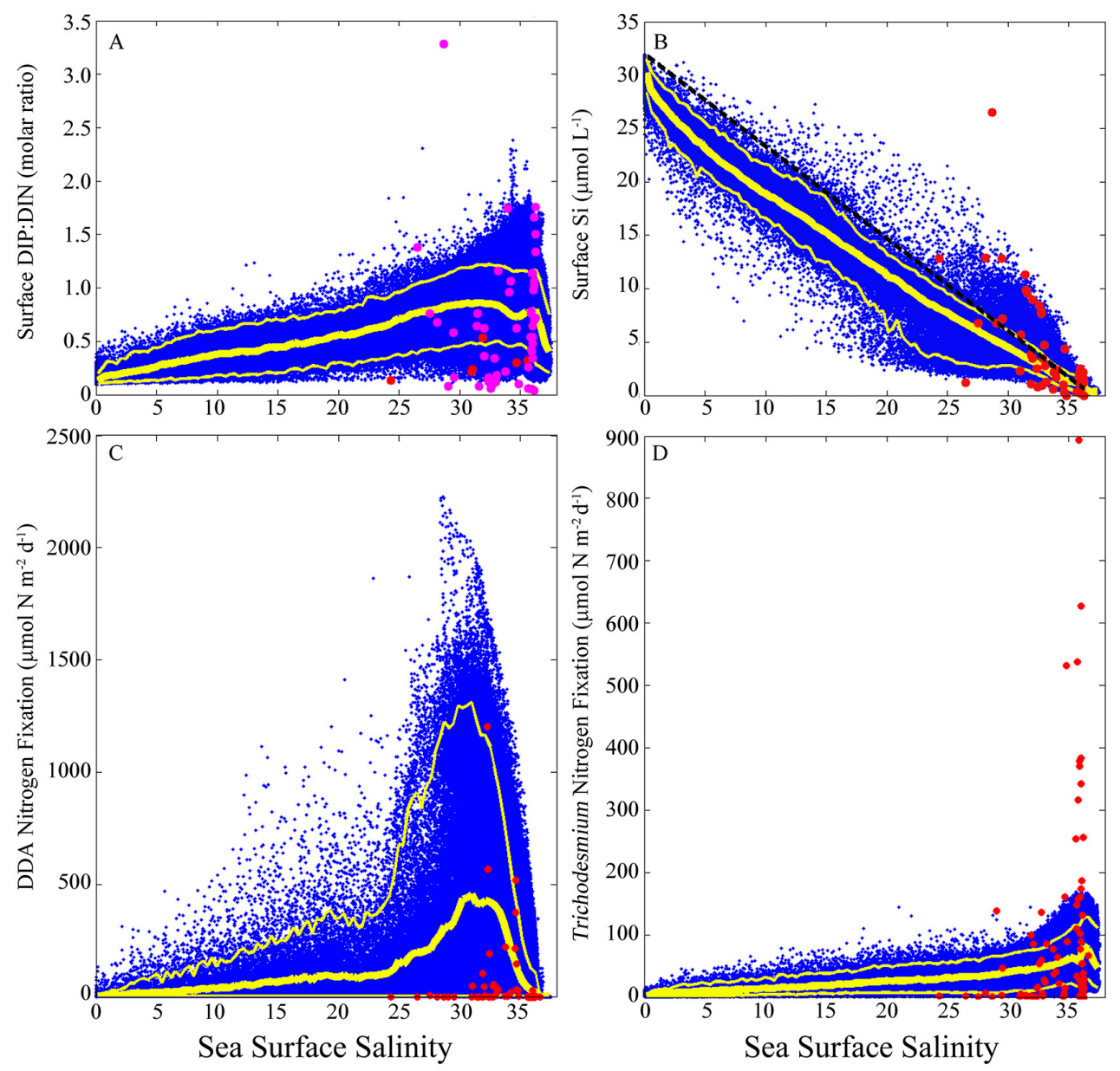

Figure 4. Model-data property-salinity comparisons in the ARP. In all plots, blue points are model values, large red dots are in situ measurements from Subramaniam et al. (2008), thick yellow line is model mean, thin yellow lines are the $95 \%$ confidence intervals. Panel (A) shows surface nutrient $\mathrm{P}: \mathrm{N}$ molar ratios. Magenta points are data points from Subramaniam et al. (2008) for which $\mathrm{NO}_{3}$ was at or below their detection limit of $0.05 \mu \mathrm{M}$. Panel (B) shows surface Si concentrations $\left(\mu \mathrm{mol} \mathrm{L}{ }^{-1}\right)$, with dashed black line showing the conservative mixing line. Panel (c) shows DDA nitrogen fixation $\left(\mu \mathrm{mol} \mathrm{N} \mathrm{m} \mathrm{m}^{-2} \mathrm{~d}^{-1}\right)$. Panel (d) shows Trichodesmium nitrogen fixation $\left(\mu \mathrm{mol} \mathrm{N} \mathrm{m} \mathrm{d}^{-1}\right)$.

less variability than the in situ measurements, though surface measured nutrients were typically near detection limits, and hence there is large uncertainty in the ratio of the measured values (Fig. 4a). The model also generally agreed with in situ DDA Nfix measurements, though it did not produce some of the highest values of Trichodesmium Nfix measured (Fig. 4d). The model predicted lower primary productivity in the low salinity regions than the in situ data $(230 \mathrm{com}-$ pared to $420 \mathrm{mg} \mathrm{C} \mathrm{m}^{-2} \mathrm{~d}^{-1}$ ), although it is worth noting that Subramaniam et al. (2008) only sampled two stations with salinity $<27$ (and only one with detectable $\mathrm{NO}_{3}$ ) and hence likely missed the early phase of the coastal blooms. Through the rest of the ARP, the in situ data suggested primary production of $\sim 700 \mathrm{mg} \mathrm{C} \mathrm{m}^{-2} \mathrm{~d}^{-1}$, with no distinct trend with salinity. Our model also suggested similarity in primary production in the meso- and oligohaline regions, but with much lower values of 188 and $163 \mathrm{mg} \mathrm{C} \mathrm{m}^{-2} \mathrm{~d}^{-1}$, respectively. It is important to note that the model community's relationship to salinity does not reflect any biological response to salinity. Instead, it reveals the importance of physical dilution processes to both nutrient and plankton concentrations in the plume.

\subsection{Phytoplankton succession in a Lagrangian framework}

Utilizing synthetic surface floats in HYCOM, we followed model parcels of river water as they were advected into the tropical North Atlantic and assessed phytoplankton successional patterns within a Lagrangian framework. Focusing on the year 1991 (determined by Coles et al. (2013) to be a typical plume year), we tracked floats for six months, with floats that ran aground within 6 months of release excluded from the following analysis (Fig. 6a).

Successional patterns along the float trajectories exhibited repeatable patterns with coastal diatom blooms 

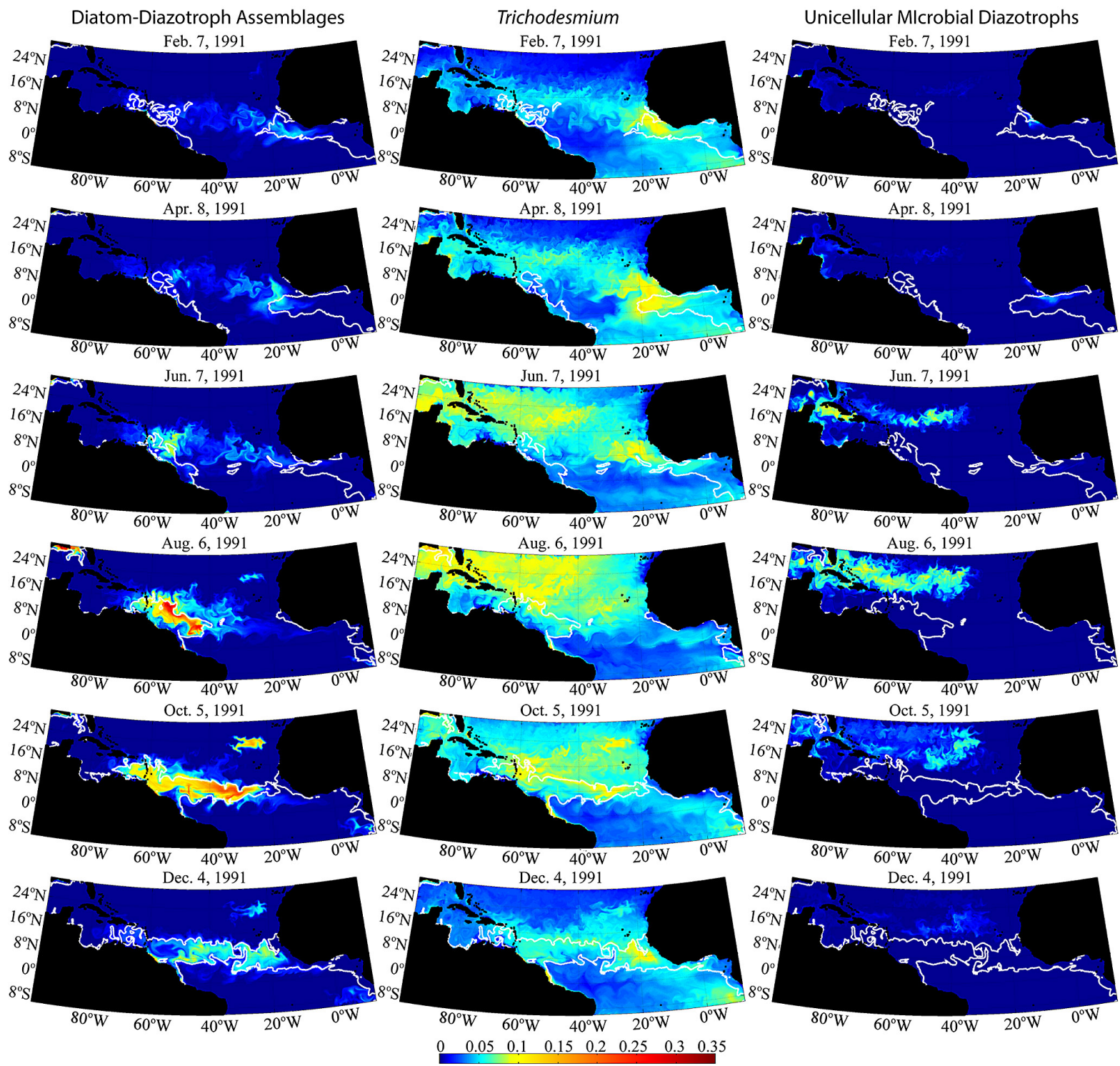

Figure 5. Seasonal variability in model surface DDAs (left), Trichodesmium (middle), and UMDs (right) concentrations ( $\mu$ mol $\mathrm{N} \mathrm{L}^{-1}$ ). White lines show the 35 salinity contour.

typically initiated within 15 days of float release. Coastal diatom blooms were associated with drawdown of DIN. Meanwhile, since DIP : DIN and Si:DIN ratios in river water were in excess of Redfield, DIP and Si exhibited patterns that suggested near conservative mixing between high nutrient river water and oligotrophic oceanic water. While cyanobacteria biomass sometimes peaked during the diatom blooms, its variability was much lower than that of diatoms. Relative contribution of cyanobacteria to total biomass was significantly greater in offshore regions. Trichodesmium typically peaked offshore (though occasional strong blooms occurred immediately after float release), often reaching highest biomass as many as three months after release of the float. Unicellular diazotrophs seldom reached substantial concentrations in floats released at the river mouth, and only bloomed several months after release.

In contrast to the highly repeatable patterns found for the other phytoplankton groups, DDA blooms were variable both in their timing and presence along float trajectories (Fig. 6b). While $25 \%$ of float trajectories never exceeded $0.085 \mu \mathrm{mol}$ DDA N L ${ }^{-1}$, another $25 \%$ exhibited DDA blooms with maximum biomass $>0.20 \mu \mathrm{mol} \mathrm{N} \mathrm{L}{ }^{-1}$. If we define this upper quartile as the float trajectories that experienced strong DDA blooms, we can begin to look at the factors controlling DDA growth. While $95 \%$ of blooms reached their peak within 75 days of release, within this window there was wide variability in the timing of the blooms. The median duration to bloom peak was 37.5 days, however $25 \%$ of the blooms reached 

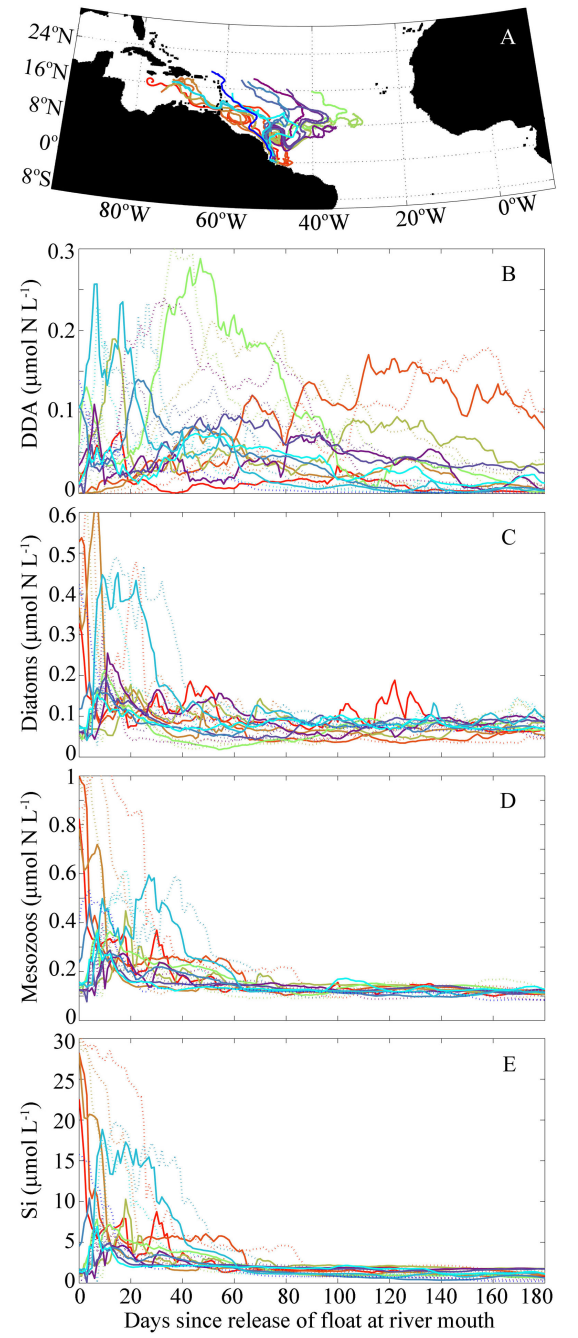

Figure 6. Float trajectories for synthetic Lagrangian floats released at river mouth. Panel (A) shows 20 randomly chosen float tracks (180 days shown for each float). Panels (B), (C), (D), and (E) show the concentration of DDAs, diatoms, mesozooplankton, and $\mathrm{Si}$, respectively experienced by these 20 random floats. Colors match between panels. For ease of differentiating individual float tracks in Panels (B-E), half of the tracks are shown as dotted rather than solid lines.

their peak within 22 days of release and another quarter of the blooms required $>50$ days to reach their peak.

While the variability in bloom timing makes it difficult to compare bloom dynamics in the temporal domain, blooms followed repetitive trajectories in the salinity domain indicating high variability in physical plume entrainment rates. A small proportion of floats experience DDA blooms at lower salinities, however most blooms are initiated at salinities $>25$ and reach peaks in salinity ranges from $30-32$. This allows us to average multiple bloom trajectories in the salinity domain to assess the factors controlling bloom formation,
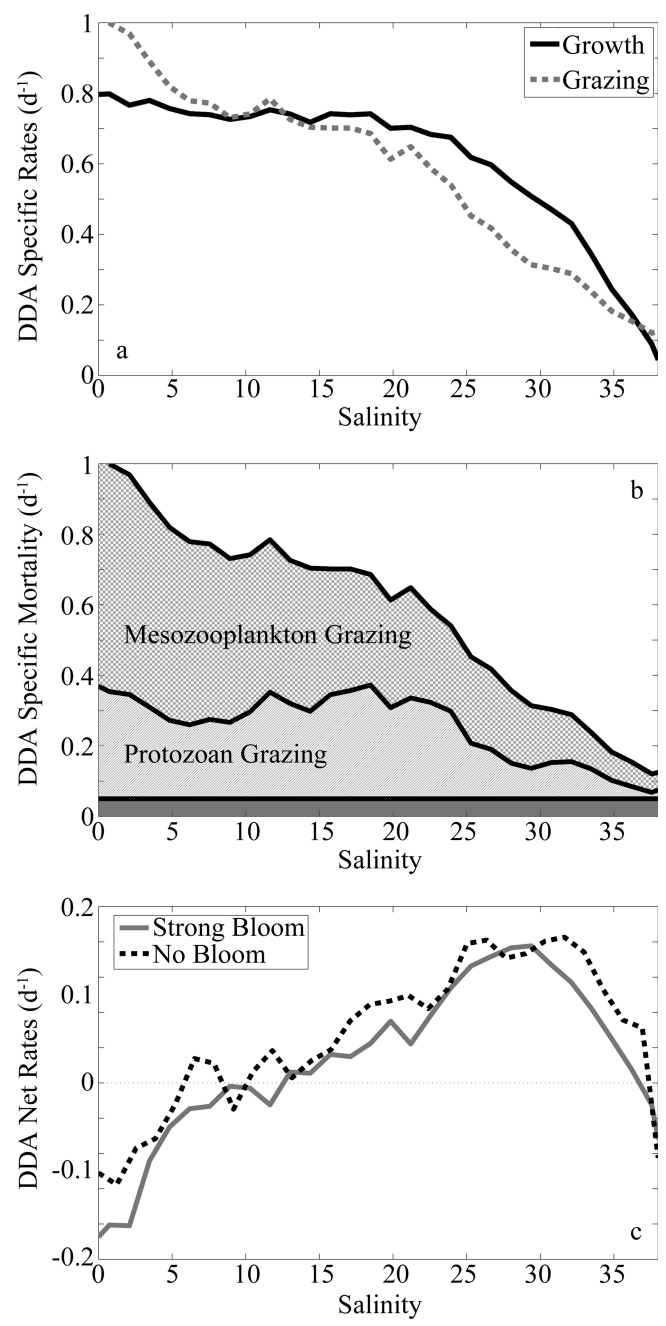

Figure 7. DDA growth and grazing rates along synthetic Lagrangian float trajectories. Panel a shows specific growth (solid black line) and mortality (gray dashed line) rates of DDAs along strong bloom float trajectories (float trajectories with max DDA biomass $>0.2 \mu \mathrm{mol} \mathrm{N} \mathrm{L}^{-1}$ ) as a function of salinity. Panel $\mathrm{b}$ subdivides the mortality rates from panel a into the following categories: natural or non-grazing mortality (solid gray bar at bottom), protozoan grazing (diagonal gray lines), and mesozooplankton grazing (gray checkerboard). Panel c compares the net growth rates along strong bloom trajectories (solid gray line) to the growth rates along non-bloom trajectories (max DDA $<0.085 \mu \mathrm{mol} \mathrm{N} \mathrm{L} \mathrm{N}^{-1}$, dashed black line).

while treating salinity as a conservative tracer for the riverocean dilution gradient.

DDA specific growth rates were highest near the river mouth where abundant nutrients led to average rates of $0.8 \mathrm{~d}^{-1}$ (Fig. 7a). They remained high until salinity reached $\sim 25$. At this point decreasing dissolved Si concentrations, driven primarily by mixing with low Si oceanic water, caused a rapid decrease in DDA specific growth rates, which continued to drop until they reached values $<0.2 \mathrm{~d}^{-1}$ in oceanic 
Table 1. Sensitivity Analysis Simulations. All parameters were consecutively halved then doubled for four month simulations run from May-August 1991 and then simulation outputs were compared to comparable outputs from the DIAZO base model run.

\begin{tabular}{|c|c|c|}
\hline Param & Description & Eq. \\
\hline$\mu_{\text {small }}$ & Maximum growth rate of all phytoplankton & 19 \\
\hline$\delta_{\text {large }: \text { small }}$ & Difference between Diatom and Cyano max growth rates & 19 \\
\hline$\delta_{\mathrm{DDA}}: \mathrm{Dtm}$ & Max growth rate of DDA & 20 \\
\hline$\theta_{\mathrm{NIF}}$ & Decrease in growth rate of DDAs when fixing $\mathrm{N}_{2}$ rather than growing on DIN & 21 \\
\hline$K_{\mathrm{L}, \mathrm{Si}}$ & Diatom half-saturation constant for $\mathrm{Si}$ & 6 and 8 \\
\hline$K_{\mathrm{S}, \mathrm{N}}$ & Cyano half-saturation constant for DIN & 2 \\
\hline$K_{\mathrm{L}, \mathrm{N}}$ & Diatom half-saturation constant for DIN & 6 \\
\hline$K_{\mathrm{S}, \mathrm{P}}$ & Cyano half-saturation constant for DIP & 2 and 4 \\
\hline$K_{\mathrm{L}, \mathrm{P}}$ & Diatom half-saturation constant for DIP & 6 and 8 \\
\hline$m_{\mathrm{PL}}$ & Intrinsic mortality of diatoms & 5 and 7 \\
\hline$I_{\mathrm{PL}}$ & Diatom growth-irradiance parameter & 6 and 8 \\
\hline$G_{\mathrm{S} 0}$ & Protozoan max grazing rate & 13 \\
\hline$G_{\mathrm{L} 0}$ & Mesozooplankton max grazing rate & 17 \\
\hline$G_{\mathrm{H} 0}$ & Higher predator max grazing rate & 15 \\
\hline$K_{\mathrm{ZS}}$ & Protozoan half-saturation constant & 13 \\
\hline$K_{\mathrm{ZL}}$ & Mesozooplankton half-saturation constant & 17 \\
\hline$\pi_{\mathrm{LL}}$ & Mesozooplankton preference for diatoms & 18 \\
\hline$\pi_{\mathrm{SS}}$ & Protozoan preference for cyanos & 14 \\
\hline Riv DIN & River DIN concentration & \\
\hline RivDIP & River DIP concentration & \\
\hline $\operatorname{Riv}_{\mathrm{Si}}$ & River Si concentration & \\
\hline
\end{tabular}

water. Surprisingly, the strong decrease in DDA growth rates from salinities of 25 to $>35$ corresponded with the region of strongest bloom formation. This apparent discrepancy is explained when comparing specific growth rates to specific mortality rates. While growth rates decrease only slowly with increasing salinity within the salinity band from 0-20, DDA specific mortality rates decrease roughly linearly with salinity. Mortality near the river mouth (Fig. 7b), driven by grazing of high concentrations of mesozooplankton supported by the coastal diatom populations, exceeded DDA growth rates. In the salinity range from 15-20, mortality decreased significantly to allow a net positive growth rate for DDAs, which then reached a maximum in net growth rate in the salinity band from 25-30 coinciding with the range where most blooms were initiated. The decrease in mesozooplankton concentrations (Fig. 6d) was driven largely by physical dilution of high-mesozooplankton coastal water with lowmesozooplankton oligotrophic water, as mesozooplankton growth exceeded grazing throughout most of the ARP. At salinities $>32$, decreasing DDA net growth rates (resulting from the sharply declining specific growth rates as $\mathrm{Si}$ limitation was induced), combined with physical dilution of the mesohaline water, led to bloom termination.

While this simple story of cessation of top-down pressure leading to bloom formation and bottom-up pressure causing bloom termination is appealing, it is not the full story. If we similarly compare specific growth and mortality rates along the float trajectories that did not experience DDA blooms (defined here as the float trajectories with max DDA concen-
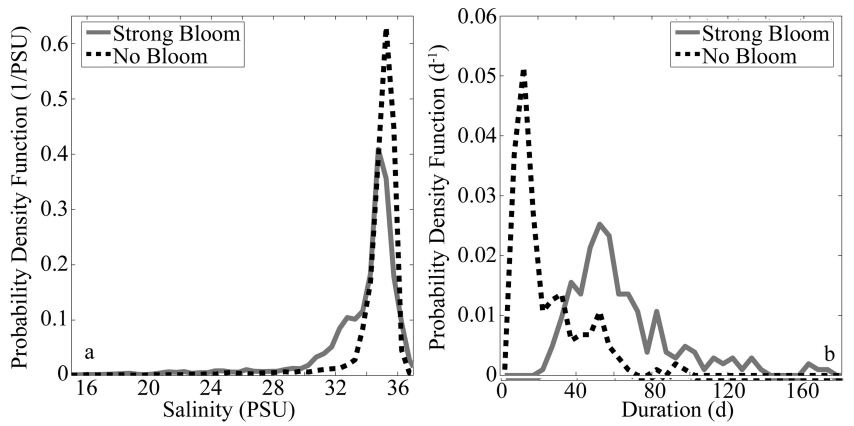

Figure 8. Float salinity histograms. Panel a shows the probability density function (PDF) of salinities experienced by synthetic Lagrangian floats in strong bloom floats (solid gray line) and nonbloom floats (dashed black line). Panel $b$ is the PDF of the duration of time that floats spend in the salinity range 20-34, which corresponds to the ideal growth conditions for DDAs.

trations $<0.085-$ e.g. the lower quartile), we find growth and mortality rates that closely match those found in the strong bloom floats (Fig. 7c). In fact, the average net growth rates in the optimal salinity band of the non-bloom floats are slightly higher than those in the bloom floats. The primary difference between the bloom and non-bloom floats was not in biological and chemical forcing, but rather in the physical transport and mixing rates. Bloom floats spent a significantly longer duration in the mesohaline region than non-bloom floats (Fig. 8), implying weaker vertical and/or horizontal 
mixing of oceanic water into the plume water for the bloom floats. The median length of time spent by non-bloom floats in the key salinity range of 20-34 was only 16 days, while all floats that experienced strong blooms spent at least 23 days in this salinity range (Fig. 8b). Only $5 \%$ of non-bloom floats spent 56 days in this salinity range, while half of the bloom floats spent longer than that period. The importance of an extended time period spent in the ideal habitat range of the DDAs is apparent from the small net growth rates of DDAs (Fig. 7c). If we assume a net growth rate of $1.1 \mathrm{~d}^{-1}$, it would take 25 days for DDA concentrations starting at the ARP region median value of $0.02 \mu \mathrm{mol} \mathrm{N} \mathrm{L}^{-1}$ to reach strong bloom values of $0.2 \mu \mathrm{mol} \mathrm{N} \mathrm{L}{ }^{-1}$, if we assume no losses to diffusion. Obviously, vertical and horizontal diffusive losses of DDAs from the core of the bloom could substantially increase the time required for bloom growth.

\subsection{Sensitivity analysis}

To assess the sensitivity of our model to parameter selections, we repeatedly ran the model over a four month period (beginning in May), which corresponded to the primary model bloom formation period in 1991. It is important to note that this four-month sensitivity analysis period (chosen as a tradeoff between duration needed to see biomass changes and computational cost) allowed time for acclimation of specific rates and for propagation of river-related biomass signals through the plume, but likely was not long enough for river-related changes to affect plume wide standing stock. During these sensitivity analyses, we sequentially doubled and halved key ecological model parameters related to phytoplankton growth rates, half saturation constants, grazing rates and selectivity, and riverine nutrient concentrations (Fig. 9, Table 1). In order to preserve niche space for each phytoplankton taxa, rather than individually scaling max phytoplankton growth rates, we re-wrote diatom and DDA max growth rates as follows:

$\mu_{\text {large }}=\mu_{\text {small }}+\delta_{\text {large }: \text { small }} \times \mu_{\text {small }}$

$\mu_{\mathrm{DDA}, \max }=\mu_{\text {large }} \times \vartheta_{L}=\mu_{\text {large }}+\delta_{\mathrm{DDA}: \mathrm{Dtm}} \times \mu_{\text {large }}$

$\mu_{\mathrm{DDA}, \text { nif }}=\mu_{\text {large }} \times \vartheta_{\text {nif }}=\mu_{\mathrm{DDA}}+\delta_{\text {nif, } \max } \times \mu_{\mathrm{DDA}}$

and varied $\mu_{\text {small }}$ (which varies all phytoplankton growth rates proportionally), $\delta_{\text {large: small (varies the ratio of Diatom }}$ and DDAs to cyanobacterial growth), $\delta_{\mathrm{DDA}}$ :Dtm (varies the ratio of DDAs to Dtm growth). We varied $\vartheta_{\text {nif }}$ directly since it does not impact DDA max growth rates, but instead their max diazotrophic growth rates. For each variable, we compared the ratios of key model standing stocks and rates (both in the ARP and across the entire basin) between the simulation and the DIAZO base model run (Fig. 9).

Sensitivity analysis showed that the model was roughly equally sensitive to parameters affecting bottom-up (max growth, half-saturation, and irradiance parameters) and topdown (max grazing, grazing saturation, and selectivity pa- rameters) control of phytoplankton (Fig. 9). The model was particularly susceptible to variations in both the absolute magnitude of phytoplankton growth rates $\left(\mu_{\text {small }}\right.$, Eq. 19) and the ratio of large: small phytoplankton growth rates $\left(\delta_{\text {large: small }}\right.$, Eq. 19$)$, and the grazing rates $\left(G_{\mathrm{S} 0}, G_{\mathrm{L} 0}\right)$ and half-saturation constants $\left(K_{\mathrm{ZS}}, K_{\mathrm{ZL}}\right)$ for both zooplankton size classes. Surprisingly, over the four month runs of our sensitivity analysis simulations, the model was relatively insensitive to changes in riverine nutrient concentrations. NFix was almost completely insensitive to changes in riverine phosphate concentrations, although this was likely due to the short duration of our simulations, combined with the fact that the two dominant taxa in the ARP (diatoms and DDAs) were not $P$-limited (Fig. 11). Altered riverine phosphate concentrations would likely have led to changes in NFix by Trichodesmium and UMDs in the oceanic regions if continued for a longer duration, but during our four month simulations there was not significant time for phosphorus to escape the plume in quantities sufficient to increase oceanic phosphate. Given likely land-use changes in the Amazon River basin, future work to assess the impact of long-term increases in river phosphorus concentrations seems warranted, but was beyond the scope of this manuscript.

In contrast to other phytoplankton taxa, DDAs responded similarly to all changes in phytoplankton growth rates with increases in $\mu_{\text {small }}, \delta_{\text {large: small }}, \delta_{\mathrm{DDA}: \mathrm{Dtm}}$, and $\vartheta_{\text {nif }}$ all leading to increases in DDA concentration. Decreases in silicate half-saturation $\left(K_{\mathrm{LSi}}\right)$ positively affected DDA concentrations, while decreases in nitrate half-saturation $\left(K_{\mathrm{LN}}\right)$ led to decreases in DDA concentrations, likely due to increased $\mathrm{Si}$ utilization by diatoms. The model was insensitive to changes in phosphorus half-saturation $\left(K_{\mathrm{S}, \mathrm{P}}\right.$ and $\left.K_{\mathrm{L}, \mathrm{P}}\right)$, because diatoms, DDAs, and cyanobacteria were not $P$-limited, while UMDs and Trichodesmium showed relatively weak nutrient limitation (Fig. 11). Altered intrinsic mortality rates $\left(m_{\mathrm{PL}}\right)$ had minimal effect on the model, reflecting the fact that phytoplankton were primarily lost to grazers. Changes in maximum grazing rates of mesozooplankton $\left(G_{\mathrm{L} 0}\right)$ and protozoans $\left(G_{S 0}\right)$ altered the relative balance of eukaryotic and prokaryotic phytoplankton, with increased mesozooplankton grazing causing a shift towards cyanobacteria and increased protozoan grazing causing a shift towards diatoms. Interestingly, increasing the maximum protozoan grazing rate $\left(G_{\mathrm{S} 0}\right)$ caused a decrease in protozoan concentrations, by driving down the total plankton standing stock of the model in a very similar pattern to the one that resulted from decreasing all phytoplankton maximum growth rates $\left(\mu_{\text {small }}\right.$, Eq. 19). Overall, the similar sensitivity of the model to phytoplankton growth and zooplankton grazing parameters supports our conclusion that both bottom-up and top-down forcing play a role in DDA blooms.

While it did not affect DDA bloom formation (and hence was not included in our sensitivity analysis), while tuning the model we discovered that the co-existence of Cya and UMDs was extremely sensitive to $\vartheta_{\mathrm{S}}$ (the ratio of UMD max growth 


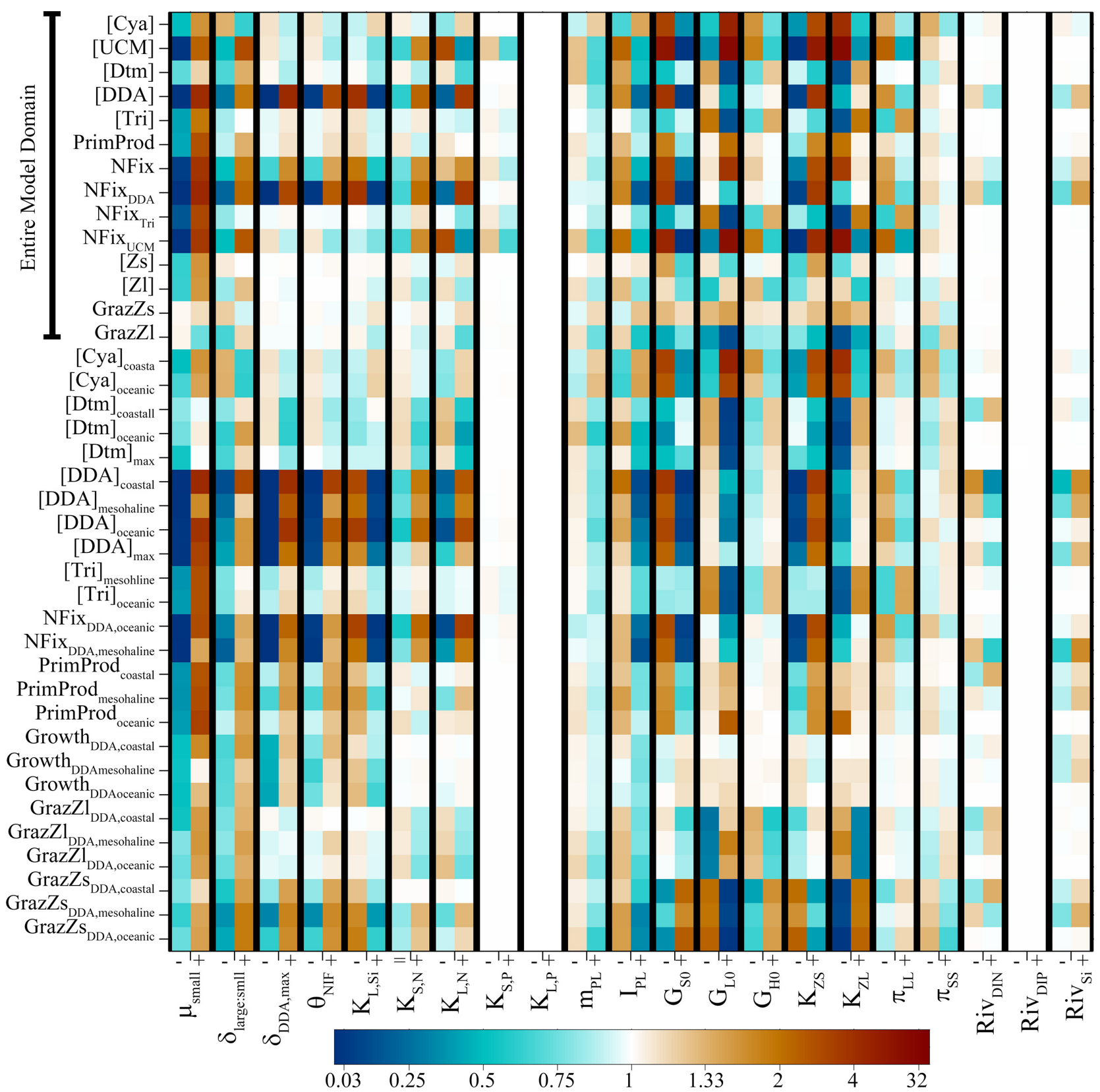

Figure 9. Sensitivity Analysis. Relationship of important model outputs (rates and standing stocks, $y$ axis) to variations in key model parameters ( $x$ axis). For each parameter, two four month simulations were conducted in which the parameter was either halved or doubled. Color axis shows the relationship of each model output at the end of the four month simulation to the equivalent model output in the DIAZO base model run. For instance, a result of 2 corresponds to a doubling relative to the DIAZO base model run standing stock or rate. First 14 outputs are averaged over the entire basin. The rest are restricted to the ARP region. Parameters varied were $\mu_{\mathrm{small}}$ (which

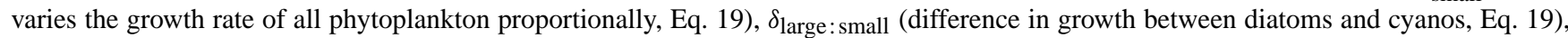
$\delta_{\text {DDA }}:$ Dtm $\left(\right.$ difference in growth between DDAs and diatoms, Eq. 20), $\theta_{\mathrm{NIF}}$ (DDA NFix penalty, Eq. 21), $K_{\mathrm{L}, \mathrm{Si}}$ (Diatom half-saturation constant for Si, Eqs. 6 and 8), $K_{\mathrm{S}, \mathrm{N}}$ (Cyano half-saturation constant for DIN, Eq. 2), $K_{\mathrm{L}, \mathrm{N}}$ (Diatom half-saturation constant for DIN, Eq. 6), $\mathrm{K}_{S, P}$ (Cyano half-saturation constant for DIP, Eqs. 2 and 4), $\mathrm{K}_{L, P}$ (Diatom half-saturation constant for DIP, Eqs. 6 and 8), $m_{\mathrm{PL}}$ (Diatom intrinsic mortality, Eqs. 5 and 7), $I_{\mathrm{PL}}$ (Diatom growth-irradiance parameter, Eqs. 6 and 8), $G_{\mathrm{S} 0}$ (Protozoan max grazing rate, Eq. 13), $G_{\mathrm{L} 0}$ (Mesozooplankton max grazing rate, Eq. 17), $G_{\mathrm{H} 0}$ (Higher predator max grazing rate, Eq. 15), $K_{\mathrm{ZS}}$ (Protozoan half-saturation constant, Eq. 13), $K_{\mathrm{ZL}}$ (Mesozooplankton half-saturation constant, Eq. 17), $\pi_{\mathrm{LL}}$ (Mesozooplankton preference for diatoms, Eq. 18), $\pi_{\mathrm{SS}}($ Protozoan

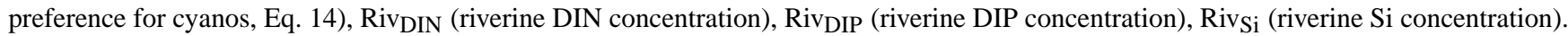


to Cya max growth). We suspect that the importance of this parameterization is due in part to our a priori decision to give UMDs and Cya identical half-saturations for phosphate. Additionally, $\mathrm{Fe}$ (which was not included in our model) is believed to be more limiting for UMDs than Cya and hence likely contributes to niche-differentiation in the ocean.

\section{Discussion}

\subsection{Modeling basin-wide diazotroph distributions}

Global and basin-scale models of diazotrophy have typically focused on Trichodesmium, a colonial cyanobacterium that grows slowly and is assumed to sustain low (if any) grazing mortality. As a result, these models often contain simplified grazing parameterizations and instead focus solely on bottom-up forcing of growth rates by phosphate and organic phosphorus availability (Ye et al., 2012), temperature (Breitbarth et al., 2007; Moore et al., 2002), and Fe deposition (Coles and Hood, 2007; Moore et al., 2006). Our model differs significantly from these previous efforts in focusing on DDAs, whose distributions may be controlled in part by predation pressure from mesozooplankton, ciliates, and other protozoa. Furthermore, in focusing specifically on the ARP region, we have been able to neglect other factors contributing to global diversity of diazotrophs. In particular, temperature is relatively constant throughout our latitudinally restricted domain and Fe is unlikely to be limiting in the plume region, though our decision not to include Fe-limitation may explain the model's tendency to overestimate nitrogen fixation in the eastern tropical North Atlantic.

While most previous models contained a single diazotroph state variable, our requirement that this model maintain populations of three distinct diazotrophs (Trichodesmium, DDAs, and unicellular microbial diazotrophs) necessitated the definition of three distinct niche spaces. Unfortunately, while Trichodesmium has been relatively well studied both in the field and in the laboratory, few comparable studies have addressed growth rates and limiting nutrients of DDAs and UMDs. The experimental evidence that exists suggests that both Crocosphaera (a UMD; Dekaezemacker and Bonnet, 2011) and diatom-Richelia symbioses (Foster et al., 2011; Villareal, 1990) have growth rates that are slower than equivalent non-diazotrophic taxa (by which we mean total non-diazotrophic cyanobacteria and diatoms, respectively). Without any compelling evidence to believe that UMDs and DDAs behave differently with respect to light or nutrient uptake kinetics (excepting $N$ ), we thus chose to model them as identical to their non-diazotrophic counterparts in these respects.

To understand how these a priori constraints on the phytoplankton community translated into realized niches in the model, we utilized principle component analysis (PCA) of the model community structure to determine the relation-
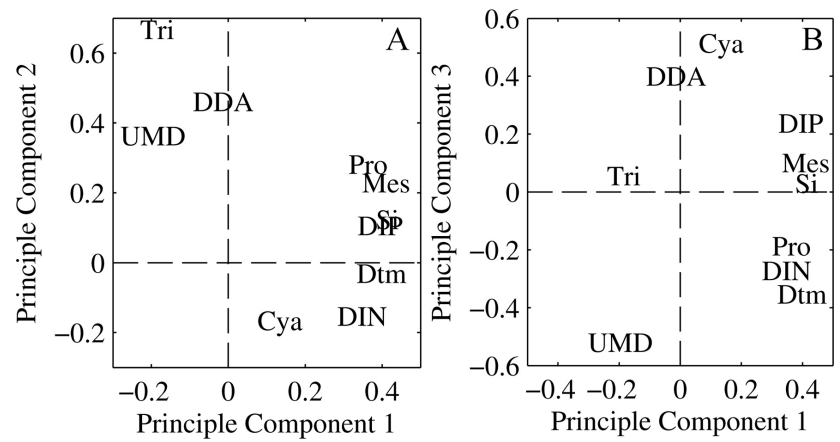

Figure 10. Principle component (PC) analysis of model nutrients and living state variables. Left panel shows PC 1 (39.5\% of the variance) on the $x$ axis and PC 2 (15.8\% of the variance) on the $y$ axis. Right panel again has PC 1 on the $\mathrm{x}$-axis, but has PC $3(12.7 \%$ of the variance) on the $y$ axis.

ships between the three nutrients and 7 plankton state variables in the model (Fig. 10). The first principle component (accounting for $39.5 \%$ of the variance) primarily divided the data set into nutrient-rich and oligotrophic regions, with diatoms and both types of zooplankton covarying with nutrients while UMDs and Trichodesmium were inversely correlated with nutrients on this axis. The second, and particularly third, principle components (accounting for 15.8 and $12.7 \%$ of the variance, respectively) begin to separate the diazotroph classes more effectively. Both PC2 and PC3 separate the nutrients based primarily on DIP: DIN ratios. In each case DDAs are correlated with DIP and anti-correlated with DIN. Along PC2, DIP and Si are correlated with each other and with all three of the diazotrophs. PC3, however, strongly differentiates the diazotrophs with DDAs correlating with the high DIP, low DIN direction (and a similar loading score to cyanobacteria), Trichodesmium showing near zero loading (indicating that their variability did not contribute significantly to PC3), and UMDs exhibiting negative loading. Overall this PCA shows that diatoms occupy the high nutrient niche in the model. Cya and DDAs both exist at intermediate nutrient levels, with DDAs specializing in high DIP : DIN ratios and cyanobacteria preferring low DIP: DIN. Trichodesmium and UMDs are both low nutrient specialists, with Trichodesmium preferring the high DIP:DIN regions and UMD excelling in the most nutrient poor regions. Interestingly, there was almost no niche overlap between diatoms and DDAs or between Cya and UMDs. In each of the first three principal components these pairs were negatively correlated, perhaps because the similar grazing pressure experienced by both types of diatoms or by both types of unicellular cyanobacteria inhibited coexistence.

To understand the origin of these patterns, we compared the nutrient limitation patterns of each phytoplankton taxa (Fig. 11). Cyanobacteria were limited by DIN throughout the model, with widely varying nutrient-limitation penalties that varied from almost no limitation in the upwelling 

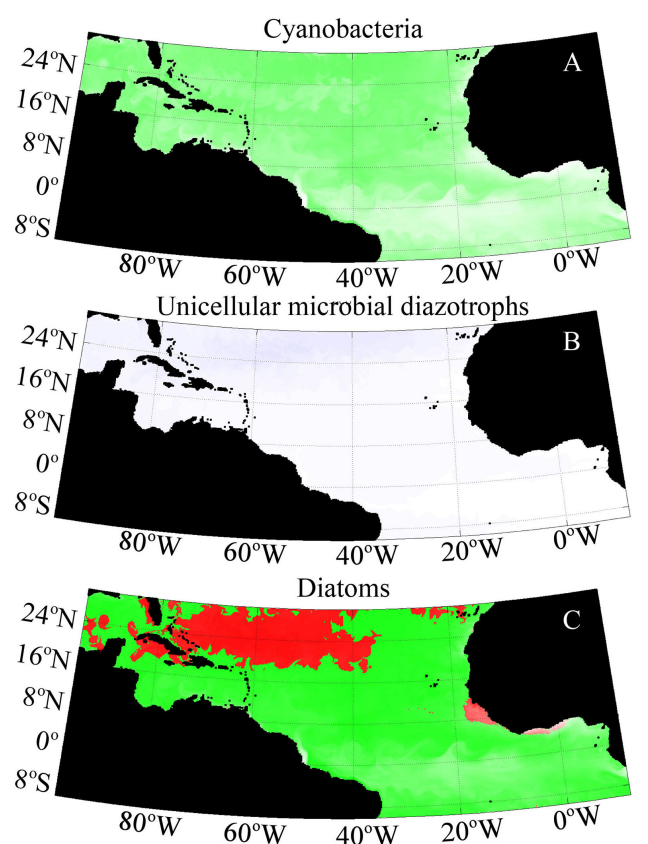

Diatom-diazotroph assemblages
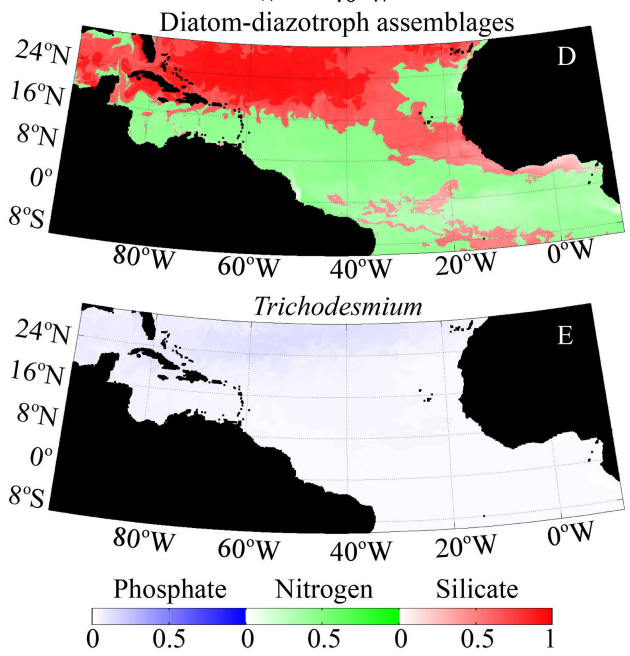

Figure 11. Nutrient limitations. Color intensity represents the degree of nutrient limitation experienced by each model phytoplankton taxa; a value of 0.75 indicates that max growth is decreased by $75 \%$ due to nutrient limitation. Color indicates the limiting nutrient (blue-phosphate, green-nitrate, red-silicate). Since DDAs are not ultimately limited by DIN, but can grow faster in its presence, we determined the limiting nutrient by calculating the partial derivative of growth with respect to each nutrient.

regions to an almost $60 \%$ decrease in growth rate in the core of the oligotrophic gyre. Non-diazotrophic diatoms, by comparison, were nutrient-limited throughout the model, exhibiting a growth penalty of $\sim 40 \%$ in even the eutrophic regions and peaking at over $90 \%$. Their limiting nutrient shifted from DIN throughout most of the region to $\mathrm{Si}$ in parts of the oligotrophic gyre and Caribbean. UMDs and Trichodesmium were phosphate- limited, but showed significantly less nutrient-limitation. Their growth rates were largely insensitive to nutrient concentration, with nutrient-related penalties seldom exceeding $10 \%$ due to their low half-saturation constant for $\mathrm{PO}_{4}^{3-}$. Unlike $\mathrm{NO}_{3}^{-}, \mathrm{PO}_{4}^{3-}$ concentrations remained high (relative to half-saturation constants), because neither UMDs nor Trichodesmium ever achieved particularly large phosphorus biomass in the model (it is important to keep in mind that all diazotrophs were parameterized with a high $\mathrm{N}: \mathrm{P}$ ratio). UMDs were kept effectively in check by protozoan grazing, while Trichodesmium production was constrained by the slow specific growth rates of this taxa. Since these organisms have high $\mathrm{N}: \mathrm{P}$ ratios, they also subsidize the growth of non-diazotrophs, further diminishing their ability to ever become community dominants. These results are consistent with in situ nutrient amendment experiments in the oligotrophic North Atlantic, which show N as the primary limiting nutrient for phytoplankton, with potential co-limitation by $P$ (Moore et al., 2008, 2013; Davey et al., 2008). Nevertheless, low $\mathrm{PO}_{4}^{3-}$ concentrations in the region, high nitrogen fixation, and co-limitation of diazotrophs by $\mathrm{P}$ and $\mathrm{Fe}$, highlight the importance of a more nuanced understanding of $\mathrm{P}$ cycling in the oligotrophic North Atlantic (Ammerman et al., 2003; Davey et al., 2008; Mills et al., 2004).

DDAs exhibited complex limitation patterns in the model due to their parameterization as a taxa that behaves as a diazotroph (but requiring $\mathrm{Si}$ ) when DIN is low, but ability to grow like a diatom when DIN is abundant. Consequently we defined their limiting nutrient as the nutrient that increased their growth the most when added in an incremental amount. By this criterion, DDAs were nitrate limited throughout most of the plume- and upwelling-affected waters where Si was replete, but Si-limited in the oligotrophic regions. Despite the stark dichotomy predicted by this definition, DDAs were in fact co-limited by Si and DIN throughout most of the model domain.

Throughout most of the model domain, these nutrientlimitation patterns largely determined the relative composition of the phytoplankton, (while the absolute magnitude was controlled by an interplay of top-down grazing control and physically-driven nutrient supply and dilution). Diatoms thrived under high nutrient loading, while cyanobacteria were dominant in lower nutrient waters, particularly those with high $\mathrm{N}: \mathrm{P}$ ratios (Fig. 12). Diazotrophs never reached the peak community dominance levels of non-diazotrophs, but filled distinct niches. UMDs excelled in the lowest nutrient waters of the model, while DDAs thrived in low DIN, high $\mathrm{Si}$ (and high $\mathrm{PO}_{4}^{3-}$ ) waters. Compared to the other taxa, Trichodesmium, contributed a relatively constant background proportion of the phytoplankton. Across the region its growth rate remained relatively constant in the range of 0.06 to $0.08 \mathrm{~d}^{-1}$. In contrast, the other low-nutrient specialist in the model (UMDs) had growth rates closer to $0.3 \mathrm{~d}^{-1}$ through- 


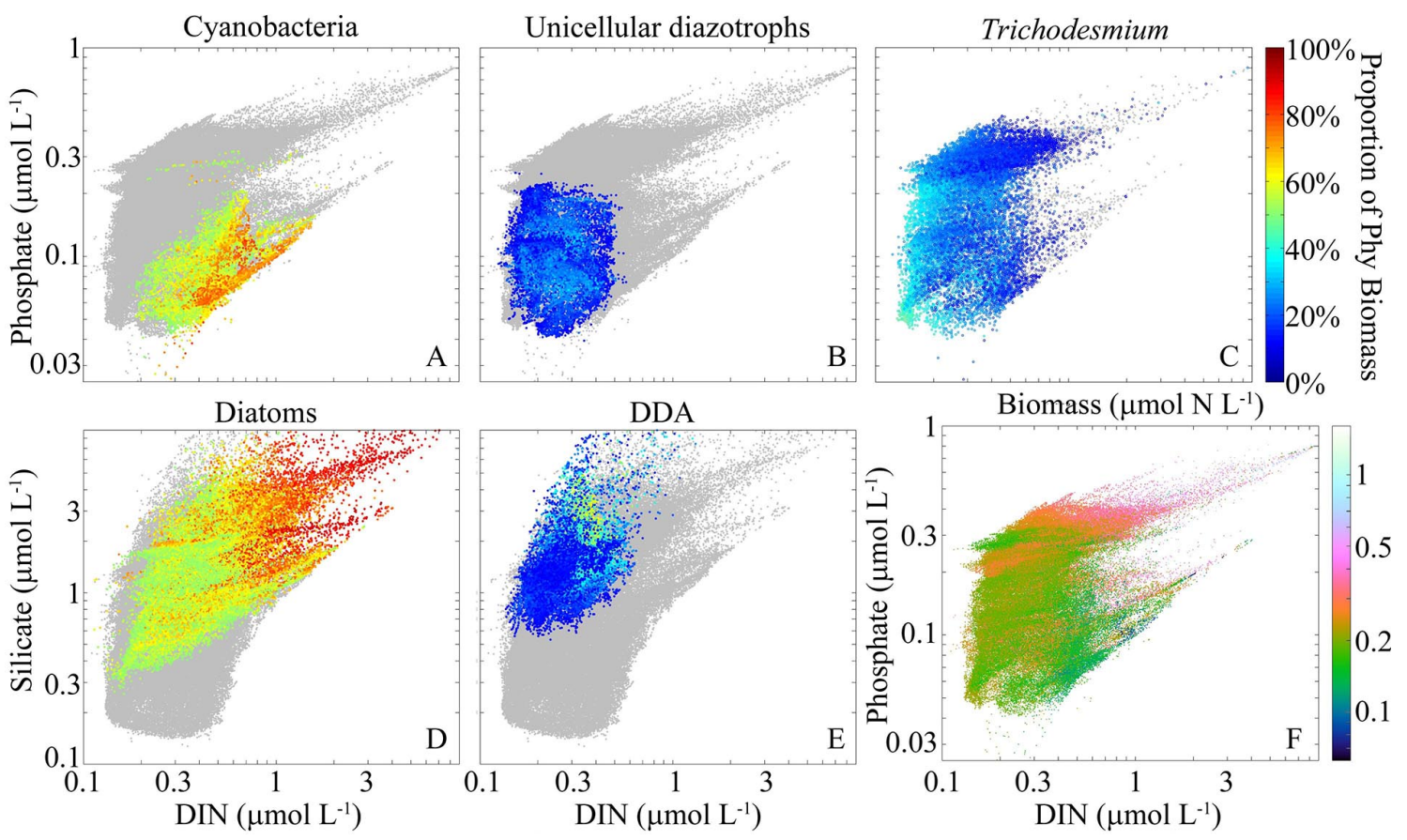

Figure 12. Phytoplankton taxa relation to nutrients - Panels (A, B, C, D, E) show the proportion of surface phytoplankton biomass comprised by cyanobactiera, unicellular microbial diazotrophs, Trichodesmium, diatoms, and diatom-diazotroph assemblages, respectively. In panels $(\mathbf{A}, \mathbf{B})$, and (C) phytoplankton proportion is plotted as a function of phosphate ( $y$ axis) and dissolved inorganic nitrogen ( $x$ axis). In panels $\mathrm{D}$ and $\mathrm{E}$, phosphate is replaced by silicate (limiting nutrient for diatom taxa). For non-diazotrophic taxa (A, D) proportions of biomass are plotted when the taxa's proportion of biomass exceeds $50 \%$. For diazotrophs $(\mathbf{B}, \mathbf{C}, \mathbf{E})$ proportions are plotted when they exceed $10 \%$. In all plots, gray values show the full extent of the model's realized nutrient-space. Panel F shows total phytoplankton biomass $\left(\mu \mathrm{mol} \mathrm{N} \mathrm{L}^{-1}\right.$ ) in the model as a function of DIN and phosphate. All plots are surface plots of values from model year 1991.

out the model domain, but suffered high grazing losses everywhere except in the most oligotrophic regions.

\subsection{Determinants of phytoplankton succession in the Amazon Plume}

Phytoplankton bloom succession in the ARP is governed by a complex inter-play of physical, bottom-up, and top-down forcing mechanisms. Given the complexity of the threedimensional physical circulation model, it is instructive to consider successional patterns in a simplified conceptual framework. The Amazon River introduces tremendous quantities of nutrient-rich water to the tropical Atlantic, but the nitrate in this source water exists at sub-Redfield ratios, and hence is quickly drawn down by blooms of coastal diatoms. This leaves nitrate-depleted, but DIP- and Si-rich, water that is ideal for DDA growth.

The DIP- and Si-rich water is entrained into the oligotrophic waters of the tropical Atlantic with mixing rates that are dependent both on the magnitude of river flux and winddriven ocean circulation (Coles et al., 2013). Only one quarter of the riverine $\mathrm{Si}$ is removed via biological drawdown in the plume, because the riverine $\mathrm{Si}: \mathrm{N}$ ratio (3.76) is much higher than the $\mathrm{Si}: \mathrm{N}$ ratio (0.48) of exported particles (at
$100 \mathrm{~m}$ ) in the plume. Thus, as Fig. 4 illustrates, Si concentrations can be approximated by a conservative mixing assumption. Furthermore, mesozooplankton (the dominant loss term for DDAs, Fig. 7) covaries with Si (Fig. 10). Mesozooplankton reach maximal concentrations in the coastal blooms near the river mouth and also exhibit a decline in concentration that can be approximated by a conservative mixing assumption. DDA net growth rates as a function of salinity can thus be estimated by considering the functional responses of DDAs to nutrients and predators, while the concentrations of both of these state variables are controlled primarily by identical physical mixing processes. We have parameterized DDA response to $\mathrm{Si}$ as a monod-type response (Eq. 8), thus the nutrient-limited growth rates of DDA decrease only slowly at low salinity/high $\mathrm{Si}$, until $\mathrm{Si}$ drops to concentrations near the half-saturation constant for DDAs $\left(2.0 \mu \mathrm{mol} \mathrm{L}^{-1}\right)$ at a salinity of $\sim 34$ (Fig. 13). After this point, growth rates begin to decrease much more rapidly. At the same time, for this simple conceptual model, we consider mesozooplankton to have the same primary loss term (dilution by low concentration oceanic water) as Si. However, the phytoplankton functional response to predators is drastically different than that to nutrients. For a given phytoplankton concentration, phytoplankton loss rates will vary linearly with zooplankton 


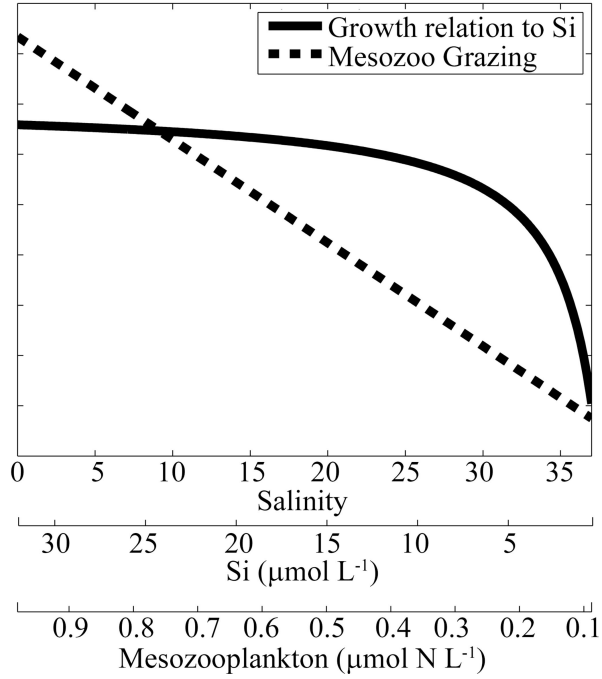

Figure 13. Conceptual diagram of the relationship of DDA growth and loss rates to conservative mixing losses of $\mathrm{Si}$ and mesozooplankton along the salinity gradient. Note that we have put no values on the $y$ axis since actual grazing rates will be dependent on the concentrations of all phytoplankton taxa and growth rates are dependent on light, both of which vary along the salinity gradient. Plot is only intended to show the different shape of DDA net growth rate responses to conservative mixing losses of nutrients and grazers.

concentration (Eq. 7), creating a mesohaline region where growth exceeds grazing. Mesohaline DDA blooms are thus an emergent property that arises from the shape of the transfer functions relating DDAs to nutrients and zooplankton, combined with the physically-driven linear loss rates of both $\mathrm{Si}$ and mesozooplankton along the salinity gradient. The crucial importance of these functional responses highlights the importance of both in situ and laboratory experiments to determine the response of DDAs to varying nutrient concentrations and grazing rates of zooplankton on DDAs.

Despite the attractive simplicity of this mechanism, it is important to point out that our model only shows that such a mechanism could account for the prevalence of DDAs in the mesohaline regions of the ARP. Other mechanisms may plausibly create a similar pattern. For instance, DDAs have at times been observed at high concentrations in the dark regions immediately beneath the plume (J. Goes, personal communication, 2011), which may suggest an adaptation to lower light conditions than most diatoms. DDAs also at times occur in regions with anomalously high (relative to conservative mixing with salinity) total phosphorus concentrations, which may suggest a utilization of other forms of phosphorus by DDAs or other taxa with which they co-occur. Utilization of DOP by alkaline-phosphatase containing diazotrophs has been included in several previous models (e.g. Coles and Hood, 2007), but was excluded in ours. In situ Lagrangian studies of DDA bloom formation may be needed to explicitly test our hypothesis.
Furthermore, our model predicts an overly rhythmic seasonal pattern, lacking the interannual variability in DDA phenology found in the ARP, and fails to produce rare, exceptionally dense blooms of all phytoplankton taxa. Inclusion of interannual variability in timing and magnitude of Amazon River discharge and seasonal variability in river nutrient concentrations may begin to explain some of these model-data discrepancies. Nevertheless, it seems that some additional mechanisms may be necessary to increase the model variance in DDA concentration. Of particular importance might be variability in mesozooplankton grazing pressure, perhaps induced by life history characteristics of dominant grazers, selectivity for or switching between diatom prey species, or density-dependent predator defense mechanisms.

DDAs have been suggested to play a distinct biogeochemical role due to their unique potential for both diazotrophy and mineral ballast driven rapid sinking rates (Subramaniam et al., 2008). In fact, massive DDA blooms have been found to co-occur with regions of high $p \mathrm{CO}_{2}$ drawdown in situ, supporting the important role of DDAs in ARP biogeochemistry (Cooley and Yager, 2006). Within the ARP region of our model, nitrogen fixation by DDAs can support $35.4 \%$ of the nitrogen exported across the 100-m depth horizon by sinking particles. Variability is high, however, with ARP region values ranging from $1.2-116 \%$ of export, and intra-regional variability even higher. Nevertheless, it is clear that DDAs introduce a significant fraction of the ARP region's new production, and hence may contribute significantly to regional carbon drawdown.

\section{Conclusions}

This is the first biogeochemical model to specifically investigate DDA populations, and with that goal came the need to parameterize zooplankton grazing in an explicit manner that is not typically utilized with models focused on diazotrophy. While our model generally agrees with the Subramaniam et al. (2008) assertion that DDA bloom in mesohaline regions with high $\mathrm{P}$ and $\mathrm{Si}$ and depleted DIN, it uncovers two additional prerequisites for bloom formation. The first is a cessation of grazing pressure due to dilution of the high coastal zooplankton abundance with oceanic, lower zooplankton abundance water. The second is a significant retention time within the mesohaline region. Unfortunately, due to the paucity of experimental evidence about DDA growth kinetics and grazing rates on DDAs, model functional parameterization was largely unconstrained by the existing data, and alternative forms of grazing and nutrient limitation functions may have been equally valid. Nevertheless the interplay of top-down, bottom-up, and physical forcing on DDAs discovered in our model can be framed as three testable hypotheses: (1) DDA specific gross growth rates will be highest near the river mouth (or in high nutrient water) and decrease along the salinity (nutrient) gradient with the greatest decreases 
in growth rate occurring at a salinity $>32$. (2) DDA specific grazing losses to mesozooplankton will be highest in the oligohaline water and decrease with increasing salinity. (3) DDA net growth rates in the mesohaline region will be low, necessitating low physical mixing rates and high retention of water parcels in the mesohaline region in order for bloom initiation. Further experimental evidence is necessary to ascertain the veracity of these mechanisms of bloom formation. It is also important to note that these prerequisites for bloom formation are likely not specific to DDAs. Niche spaces for all phytoplankton taxa are a function of inequity in growth and mortality, and the duration of time spent in these niche spaces may be as critical to bloom formation as the magnitude of the growth-grazing imbalance.

\section{The Supplement related to this article is available online at doi:10.5194/bg-11-3259-2014-supplement.}

Acknowledgements. We would like to thank our many collaborators from the ANACONDAS program for their thoughtful contributions to this project. In particular, we would like to thank P. Yager, J. Goes, D. Steinberg, J. Montoya, and E. Carpenter for insightful conversations that informed the preparation of this manuscript. We are also indebted to two anonymous reviewers whose helpful comments greatly strengthened this manuscript. This work was supported by NSF Grant OCE0933975 and by the Gordon and Betty Moore Foundation through Grants GBMF2293 and GBMF2928 to V. Coles and R. Hood. Our model code can be found on Source Forge: http: //sourceforge.net/projects/anacondas/files/ANACONDAS-DDA/. This manuscript is UMCES contribution \#4902.

Edited by: L. Cotrim da Cunha

\section{References}

Ammerman, J. W., Hood, R. R., Case, D. A., and Cotner, J. B.: Phosphorus deficiency in the Atlantic: An emerging paradigm in oceanography, EOS, Transactions, Am. Geophys. Union, 84, 165-170, 2003.

Aumont, O., Maier-Reimer, E., Blain, S., and Monfray, P.: An ecosystem model of the global ocean including $\mathrm{Fe}$, Si, P colimitations, Global Biogeochem. Cy., 17, 1060, doi:10.1029/2001gb001745, 2003.

Breitbarth, E., Oschlies, A., and LaRoche, J.: Physiological constraints on the global distribution of Trichodesmium - effect of temperature on diazotrophy, Biogeosciences, 4, 53-61, doi:10.5194/bg-4-53-2007, 2007.

Calbet, A.: Mesozooplankton grazing effect on primary production: A global comparative analysis in marine ecosystems, Limnol. Oceanogr., 46, 1824-1830, 2001.

Calbet, A. and Landry, M. R.: Phytoplankton growth, microzooplankton grazing, and carbon cycling in marine systems, Limnol. Oceanogr., 49, 51-57, 2004.
Calbet, A., Atienza, D., Henriksen, C. I., Saiz, E., and Adey, T. R.: Zooplankton grazing in the Atlantic Ocean: A latitudinal study, Deep-Sea Res. Part II-Top, Stud. Oceanogr., 56, 954-963, 2009.

Capone, D. G., Burns, J. A., Montoya, J. P., Subramaniam, A., Mahaffey, C., Gunderson, T., Michaels, A. F., and Carpenter, E. J.: Nitrogen fixation by Trichodesmium spp.: An important source of new nitrogen to the tropical and subtropical North Atlantic Ocean, Global Biogeochem. Cy., 19, GB2024, doi:10.1029/2004gb002331, 2005.

Carpenter, E. J., Montoya, J. P., Burns, J., Mulholland, M. R., Subramaniam, A., and Capone, D. G.: Extensive bloom of a N-2-fixing diatom/cyanobacterial association in the tropical Atlantic Ocean, Mar. Ecol.-Prog. Ser., 185, 273-283, 1999.

Coles, V. J. and Hood, R. R.: Modeling the impact of iron and phosphorus limitations on nitrogen fixation in the Atlantic Ocean, Biogeosciences, 4, 455-479, doi:10.5194/bg-4-455-2007, 2007.

Coles, V. J., Brooks, M. T., Hopkins, J., Stukel, M. R., Yager, P. L., and Hood, R. R.: The pathways and properties of the Amazon River Plume in the tropical North Atlantic Ocean, J. Geophys. Res. Oceans, 118, 6894-6913, 2013.

Cooley, S. R. and Yager, P. L.: Physical and biological contributions to the western tropical North Atlantic Ocean carbon sink formed by the Amazon River plume, J. Geophys. Res. Oceans, 111, C08018, doi:10.1029/2005jc002954, 2006.

Davenport, R., Neuer, S., Helmke, P., Perez-Marrero, J., and Llinas, O.: Primary productivity in the northern Canary Islands region as inferred from SeaWiFS imagery, Deep-Sea Res. Part II-Top. Stud. Oceanogr., 49, 3481-3496, 2002.

Davey, M., Tarran, G. A., Mills, M. M., Ridame, C., Geider, R. J., and LaRoche, J.: Nutrient limitation of picophytoplankton photosynthesis and growth in the tropical North Atlantic, Limnol. Oceanogr., 53, 1722-1733, 2008.

Dekaezemacker, J. and Bonnet, S.: Sensitivity of $\mathrm{N}_{2}$ fixation to combined nitrogen forms $\left(\mathrm{NO}_{3}^{-}\right.$and $\left.\mathrm{NH}_{4}^{+}\right)$in two strains of the marine diazotroph Crocosphaera watsonii (Cyanobacteria), Mar. Ecol. Prog. Ser., 438, 33-46, 2011.

Falcon, L. I., Carpenter, E. J., Cipriano, F., Bergman, B., and Capone, D. G.: N-2 fixation by unicellular bacterioplankton from the Atlantic and Pacific oceans: Phylogeny and in situ rates, Appl. Environ. Microbiol., 70, 765-770, 2004.

Fasham, M. J. R., Ducklow, H.W., and McKelvie, S. M.: A Nitrogen-Based Model of Plankton Dynamics in the Oceanic Mixed Layer, J. Mar. Res., 48, 591-639, 1990.

Fernandez, A., Mourino-Carballido, B., Bode, A., Varela, M., and Maranon, E.: Latitudinal distribution of Trichodesmium spp. and $\mathrm{N}_{2}$ fixation in the Atlantic Ocean, Biogeosciences, 7, 3167 3176, doi:10.5194/bg-7-3167-2010, 2010.

Foster, R. A. and O'Mullan, G. D.: Nitrogen-fixing and nitrifying symbioses in the marine environment, in: Nitrogen in the Marine Environment, 2nd Edn., edited by: Capone, D. G., Bronk, D. A., Mulholland, M. R., and Carpenter, E. J., Academic Press, Burlington, MA, 2008.

Foster, R. A., Kuypers, M. M., Vagner, T., Paerl, R. W., Musat, N., and Zehr, J. P.: Nitrogen fixation and transfer in open ocean diatom-cyanobacterial symbioses, Isme J., 5, 1484-1493, 2011.

Halliwell, G. and Garraffo, Z.: Synthetic floats, drifters, and moorings in HYCOM: http://hycom.org/attachments/067_float. pdf (last access: 18 April 2013), 2002. 
Hood, R. R., Bates, N. R., Capone, D. G., and Olson, D. B.: Modeling the effect of nitrogen fixation on carbon and nitrogen fluxes at BATS, Deep-Sea Res. II, 48, 1609-1648, 2001.

Hood, R. R., Coles, V. J., and Capone, D. G.: Modeling the distribution of Trichodesmium and nitrogen fixation in the Atlantic Ocean, J. Geophys. Res. Oceans, 109, C06006, doi:10.1029/2002jc001753, 2004.

Hu, C. M., Montgomery, E. T., Schmitt, R. W., and Muller-Karger, F. E.: The dispersal of the Amazon and Orinoco River water in the tropical Atlantic and Caribbean Sea: Observation from space and S-PALACE floats, Deep-Sea Res. Part II-Top. Stud. Oceanogr., 51, 1151-1171, 2004.

Huskin, I., Anadon, R., Woodd-Walker, R. S., and Harris, R. P.: Basin-scale latitudinal patterns of copepod grazing in the Atlantic Ocean, J. Plankton Res., 23, 1361-1371, 2001.

Isla, J. A., Llope, M., and Anadon, R.: Size-fractionated mesozooplankton biomass, metabolism and grazing along a 50 degrees N-30 degrees S transect of the Atlantic Ocean, J. Plankton Res., 26, 1301-1313, 2004.

Kemp, A. E. S. and Villareal, T. A.: High diatom production and export in stratified waters - A potential negative feedback to global warming, Prog. Oceanogr., 119, 4-23, 2013.

Lopez, E. and Anadon, R.: Copepod communities along an Atlantic Meridional Transect: Abundance, size structure, and grazing rates, Deep-Sea Res. Part I-Oceanogr. Res. Pap., 55, 13751391, 2008.

Luo, Y.-W., Doney, S. C., Anderson, L. A., Benavides, M., BermanFrank, I., Bode, A., Bonnet, S., Boström, K. H., Böttjer, D., Capone, D. G., Carpenter, E. J., Chen, Y. L., Church, M. J., Dore, J. E., Falcón, L. I., Fernández, A., Foster, R. A., Furuya, K., Gómez, F., Gundersen, K., Hynes, A. M., Karl, D. M., Kitajima, S., Langlois, R. J., LaRoche, J., Letelier, R. M., Marañón, E., McGillicuddy Jr., D. J., Moisander, P. H., Moore, C. M., Mouriño-Carballido, B., Mulholland, M. R., Needoba, J. A., Orcutt, K. M., Poulton, A. J., Rahav, E., Raimbault, P., Rees, A. P., Riemann, L., Shiozaki, T., Subramaniam, A., Tyrrell, T., TurkKubo, K. A., Varela, M., Villareal, T. A., Webb, E. A., White, A. E., Wu, J., and Zehr, J. P.: Database of diazotrophs in global ocean: abundance, biomass and nitrogen fixation rates, Earth Syst. Sci. Data, 4, 47-73, doi:10.5194/essd-4-47-2012, 2012.

Marañon, E., Perez, V., Fernandez, E., Anadon, R., Bode, A., Gonzalez, N., Huskin, I., Isla, A., Moran, X. A. G., Mourino, B., Quevedo, M., Robinson, C., Serret, P., Teira, E., Varela, M. M., Woodward, E. M. S., and Zubkov, M. V.: Planktonic carbon budget in the eastern subtropical North Atlantic, Aquat. Microb. Ecol., 48, 261-275, 2007.

Mills, M. M., Ridame, C., Davey, M., La Roche, J., and Geider, R. J.: Iron and phosphorus co-limit nitrogen fixation in the eastern tropical North Atlantic, Nature, 429, 292-294, 2004.

Monteiro, F. M., Follows, M. J., and Dutkiewicz, S.: Distribution of diverse nitrogen fixers in the global ocean, Global Biogeochem. Cy., 24, 16, Gb3017 doi:10.1029/2009gb003731, 2010.

Montoya, J. P., Voss, M., and Capone, D. G.: Spatial variation in N2-fixation rate and diazotroph activity in the Tropical Atlantic, Biogeosciences, 4, 369-376, doi:10.5194/bg-4-369-2007, 2007.

Moore, C. M., Mills, M. M., Langlois, R., Milne, A., Achterberg, E. P., La Roche, J., and Geider, R. J.: Relative influence of nitrogen and phosphorus availability on phytoplankton physiology and productivity in the oligotrophic sub-tropical North Atlantic Ocean, Limnol. Oceanogr., 53, 291-305, 2008.

Moore, C. M., Mills, M. M., Achterberg, E. P., Geider, R. J., LaRoche, J., Lucas, M. I., McDonagh, E. L., Pan, X., Poulton, A. J., Rijkenberg, M. J. A., Suggett, D. J., Ussher, S. J., and Woodward, E. M. S.: Large-scale distribution of Atlantic nitrogen fixation controlled by iron availability, Nat. Geosci., 2, 867-871, 2009.

Moore, C. M., Mills, M. M., Arrigo, K. R., Berman-Frank, I., Bopp, L., Boyd, P.W., Galbraith, E. D., Geider, R. J., Guieu, C., Jaccard, S. L., Jickells, T. D., La Roche, J., Lenton, T. M., Mahowald, N. M., Maranon, E., Marinov, I., Moore, J. K., Nakatsuka, T., Oschlies, A., Saito, M. A., Thingstad, T. F., Tsuda, A., and Ulloa, O.: Processes and patterns of oceanic nutrient limitation, Nat. Geosci., 6, 701-710, 2013.

Moore, J. K., Doney, S. C., Kleypas, J. A., Glover, D. M., and Fung, I. Y.: An intermediate complexity marine ecosystem model for the global domain, Deep-Sea Res. Part II-Top. Stud. Oceanogr., 49, 403-462, 2002.

Moore, J. K., Doney, S. C., Lindsay, K., Mahowald, N., and Michaels, A. F.: Nitrogen fixation amplifies the ocean biogeochemical response to decadal timescale variations in mineral dust deposition, Tellus Ser. B-Chem. Phys. Meteorol., 58, 560-572, 2006.

Neuer, S., Freudenthal, T., Davenport, R., Llinas, O., and Rueda, M. J.: Seasonality of surface water properties and particle flux along a productivity gradient off NW Africa, Deep-Sea Res. Part II-Top. Stud. Oceanogr., 49, 3561-3576, 2002.

Perez, V., Fernandez, E., Maranon, E., Serret, P., Varela, R., Bode, A., Varela, M., Varela, M. M., Moran, X. A. G., Woodward, E. M. S., Kitidis, V., and Garcia-Soto, C.: Latitudinal distribution of microbial plankton abundance, production, and respiration in the Equatorial Atlantic in Autumn 2000, Deep-Sea Res. Part IOceanogr. Res. Pap., 52, 861-880, 2005.

Perez, V., Fernandez, E., Maranon, E., Moran, X. A. G., and Zubkovc, M. V.: Vertical distribution of phytoplankton biomass, production and growth in the Atlantic subtropical gyres, DeepSea Res. Part I-Oceanogr. Res. Pap., 53, 1616-1634, 2006.

Perry, G. D., Duffy, P. B., and Miller, N. L.: An extended data set of river discharges for validation of general circulation models, J. Geophys. Res.-Atmos., 101, 21339-21349, 10.1029/96jd00932, 1996.

Poulton, A. J., Holligan, P. M., Hickman, A., Kim, Y. N., Adey, T. R., Stinchcombe, M. C., Holeton, C., Root, S., and Woodward, E. M. S.: Phytoplankton carbon fixation, chlorophyll-biomass and diagnostic pigments in the Atlantic Ocean, Deep-Sea Res. II, 53, 1593-1610, 2006.

Quevedo, M. and Anadón, R.: Protist control of phytoplankton growth in the subtropical north-east Atlantic, Mar. Ecol. Prog. Ser., 221, 29-38, 2001.

Rijkenberg, M. J. A., Langlois, R. J., Mills, M. M., Patey, M. D., Hill, P. G., Nielsdottir, M. C., Compton, T. J., LaRoche, J., and Achterberg, E. P.: Environmental Forcing of Nitrogen Fixation in the Eastern Tropical and Sub-Tropical North Atlantic Ocean, PLoS One, 6, e28989 doi:10.1371/journal.pone.0028989, 2011.

Steele, M., Morley, R., and Ermold, W.: PHC: A Global Ocean Hydrography with a High-Quality Arctic Ocean, J. Climate, 14, 2079-2087, 2001. 
Stock, C. and Dunne, J.: Controls on the ratio of mesozooplankton production to primary production in marine ecosystems, DeepSea Res. I, 57, 95-112, 2010.

Subramaniam, A., Yager, P. L., Carpenter, E. J., Mahaffey, C., Bjorkman, K., Cooley, S., Kustka, A. B., Montoya, J. P., SanudoWilhelmy, S. A., Shipe, R., and Capone, D. G.: Amazon River enhances diazotrophy and carbon sequestration in the tropical North Atlantic Ocean, Proc. Natl. Acad. Sci. USA, 105, 1046010465, 2008.

Teira, E., Mourino, B., Maranon, E., Perez, V., Pazo, M. J., Serret, P., de Armas, D., Escanez, J., Woodward, E. M. S., and Fernandez, E.: Variability of chlorophyll and primary production in the Eastern North Atlantic Subtropical Gyre: potential factors affecting phytoplankton activity, Deep-Sea Res. Part I-Oceanogr. Res. Pap., 52, 569-588, 2005.

Tilstone, G., Smyth, T., Poulton, A., and Hutson, R.: Measured and remotely sensed estimates of primary production in the Atlantic Ocean from 1998 to 2005, Deep-Sea Res. Part II-Top. Stud. Oceanogr., 56, 918-930, 2009.
Turk, K. A., Rees, A. P., Zehr, J. P., Pereira, N., Swift, P., Shelley, R., Lohan, M., Woodward, E. M. S., and Gilbert, J.: Nitrogen fixation and nitrogenase (nifH) expression in tropical waters of the eastern North Atlantic, Isme J., 5, 1201-1212, 2011.

Villareal, T. A.: Laboratory culture and preliminary characterization of the nitrogen-fixing Rhizosolenia-Richelia symbiosis, Mar. Ecol., 11, 117-132, 1990.

Ye, Y., Volker, C., Bracher, A., Taylor, B., and Wolf-Gladrow, D. A.: Environmental controls on N-2 fixation by Trichodesmium in the tropical eastern North Atlantic Ocean-A model-based study, Deep-Sea Res. Part I-Oceanogr. Res. Pap., 64, 104-117, 2012.

Yoshikawa, C., Coles, V. J., Hood, R. R., Capone, D. G., and Yoshida, N.: Modeling how surface nitrogen fixation influences subsurface nutrient patterns in the North Atlantic, J. Geophys. Res.,Oceans, 118, 2520-2534, 2013. 